\title{
CCG.CGG interruptions in high-penetrance SCA8 families increase RAN translation and protein toxicity
}

\author{
Barbara A Perez $z^{1,2, \dagger}$, Hannah K Shorrock ${ }^{1,2, \dagger}$ (D), Monica Banez-Coronel ${ }^{1,2}$, Tao Zu ${ }^{1,2}$ (D), \\ Lisa EL Romano ${ }^{1,2}$, Lauren A Laboissonniere ${ }^{1,2}$, Tammy Reid ${ }^{1,2}$, Yoshio Ikeda $^{3}$, Kaalak Reddy ${ }^{4}$, \\ Christopher M Gomez ${ }^{5}$ D , Thomas Bird ${ }^{6,7}$, Tetsuo Ashizawa ${ }^{8}$ iD, Lawrence J Schut ${ }^{9}$, \\ Alfredo Brusco ${ }^{10,11}$ (D), J Andrew Berglund ${ }^{1,4}$, Lis F Hasholt ${ }^{12}$, jorgen E Nielsen ${ }^{13}$ (D), SH Subramony ${ }^{1,14}$ \& \\ Laura PW Ranum ${ }^{1,2,14,15,{ }^{*} \text { (iD }}$
}

\begin{abstract}
Spinocerebellar ataxia type 8 (SCA8), a dominantly inherited neurodegenerative disorder caused by a CTG.CAG expansion, is unusual because most individuals that carry the mutation do not develop ataxia. To understand the variable penetrance of SCA8, we studied the molecular differences between highly penetrant families and more common sporadic cases (82\%) using a large cohort of SCA8 families $(n=77)$. We show that repeat expansion mutations from individuals with multiple affected family members have CCG.CGG interruptions at a higher frequency than sporadic SCA8 cases and that the number of CCG.CGG interruptions correlates with age at onset. At the molecular level, CCG.CGC interruptions increase RNA hairpin stability, and in cell culture experiments, increase p-elF $2 \alpha$ and polyAla and polySer RAN protein levels. Additionally, CCG.CGC interruptions, which encode arginine interruptions in the polyGln frame, increase toxicity of the resulting proteins. In summary, SCA8 CCG.CGG interruptions increase polyAla and polySer RAN protein levels, polyGln protein toxicity, and disease penetrance and provide novel insight into the molecular differences between SCA8 families with high vs. low disease penetrance.
\end{abstract}

Keywords cis-modifier; RAN translation; reduced penetrance; sequence interruptions; spinocerebellar ataxia type 8

Subject Categories Genetics, Gene Therapy \& Genetic Disease; Neuroscience DOI 10.15252/emmm.202114095 | Received 7 February 2021 | Revised 9 September 2021 | Accepted 10 September 2021 | Published online 11 October 2021

EMBO Mol Med (2021) 13: e14095

\section{Introduction}

Spinocerebellar ataxia type 8 (SCA8) is a microsatellite expansion disorder caused by a bidirectionally transcribed $\mathrm{CTG} \bullet \mathrm{CAG}$ repeat expansion mutation within the ATXN8OS/ATXN8 genes (Koob et al, 1999; Moseley et al, 2006). This slowly progressive cerebellar ataxia is typically characterized by ataxia, spasticity, dysarthria, and nystagmus; however, extra-cerebellar features including psychiatric disturbances and developmental delays have been reported (Day et al, 2000; Juvonen et al, 2000; Stone et al, 2001; Lilja et al, 2005; Koutsis et al, 2012; Kim et al, 2013; Cleary et al, 2021; Zhou et al, 2019). Although SCA8 is caused by a dominantly inherited mutation, patients frequently have no family history of ataxia and are referred to as sporadic cases. Despite the negative family history,

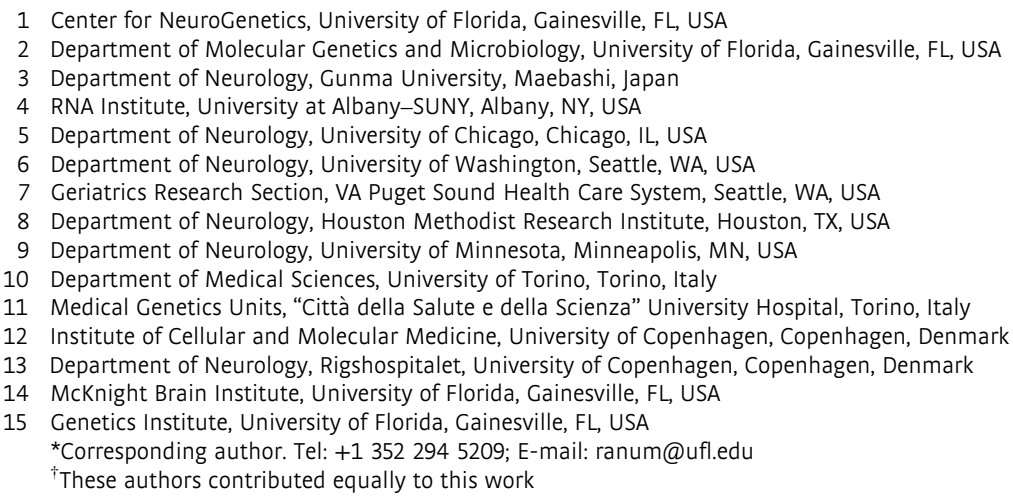


repeat expansion mutations are almost always found in asymptomatic relatives of these sporadic cases (Koob et al, 1999; Moseley et al, 2000b; Worth et al, 2000; Ikeda et al, 2004). Additionally, the age of onset and clinical features of the disease vary widely among affected individuals, with onset reported from birth to 73 years of age (Koob et al, 1999; Day et al, 2000; Ikeda et al, 2000, 2004; Silveira et al, 2000; Felling \& Barron, 2005; Lilja et al, 2005; Kim et al, 2013; Samukawa et al, 2019).

Repeat-associated non-AUG (RAN) proteins, which were first discovered in SCA8 and DM1 ( $\mathrm{Zu}$ et al, 2011), have now been described in 11 microsatellite expansion disorders (Zu et al, 2011, 2017; Mori et al, 2013; Todd et al, 2013; Banez-Coronel et al, 2015; Buijsen et al, 2016; Ishiguro et al, 2017; Banez-Coronel \& Ranum, 2019; Goodman \& Bonini, 2019; McEachin et al, 2020). RAN translation is a process in which transcripts containing repeat expansions express proteins in multiple reading frames without the requirement of AUG- or AUG-like close-cognate initiation codons (Zu et al, 2011, 2018; Cleary et al, 2018; Banez-Coronel \& Ranum, 2019; Nguyen et al, 2019). The presence of RAN and ATG-initiated expansion proteins has been previously reported in human SCA8 autopsy brains and SCA8-BAC transgenic mice (Moseley et al, 2006; Zu et al, 2011; Ayhan et al, 2018). Both ATG-initiated polyglutamine (polyGln) and RAN poly-Alanine (polyAla) proteins are found in Purkinje cells (Moseley et al, 2006; Zu et al, 2011) and polyGln and RAN poly-Serine (polySer) proteins are detected in the hippocampus, pons, and frontal cortex (Ayhan et al, 2018). Additionally, polySer aggregates accumulate in the cerebellar white matter and brainstem nuclei where they are associated with demyelination, axonal degeneration, increased astrogliosis, and a reduction in the number of mature oligodendrocytes (Ayhan et al, 2018).

In contrast to other SCAs, SCA8 is unusual in that there is markedly reduced penetrance (Koob et al, 1999; Stevanin et al, 2000; Worth et al, 2000; Ikeda et al, 2004), suggesting that genetic and/or environmental modifiers affect the onset and penetrance of SCA8. One potential genetic modifier that may affect disease penetrance in SCA8 is the presence of repeat interruptions. The presence of CCG, CTA, CTC, CCA, and CTT interruptions in the CTG repeat expansion in SCA8 have previously been reported (Moseley et al, 2000b; Hu et $a l, 2017)$. These interruptions can vary in number, configuration, and position within the repeat tract. Interestingly, one to four CCG interruptions were detected in multiple configurations among affected members of a large, highly penetrant SCA8 family (MN-A) and the number of interruptions often increases when passed from one generation to the next (Moseley et al, 2000b).

Repeat interruptions have been reported to have different modifying effects in a number of other microsatellite expansion disorders. For example in SCA1, SCA2, and fragile-X syndrome (FXS), sequence interruptions appear to stabilize unexpanded repeat tracts, and the loss of interruptions predisposes repeat tracts to expand above the pathogenic threshold (Chung et al, 1993; Kunst \& Warren, 1994; Imbert et al, 1996; Pulst et al, 1996; Sanpei et al, 1996; Gunter et al, 1998). In other cases, interruptions are found on expanded alleles and are associated with changes in disease presentation. For example, CAA interruptions on expanded alleles are associated with later ages of onset in SCA2 (Sobczak \& Krzyzosiak, 2005) and Huntington disease (Genetic Modifiers of Huntington's Disease, 2019; Wright et al, 2019). In SCA10, patients with ATCCT interruptions are prone to seizures (McFarland et al, 2014), and in DM1, CCG and
GGC interruptions are found in patients with peripheral neuropathy (Braida et al, 2010), but the molecular basis for these effects is unclear.

Here, we show that CCG $\bullet$ CGG interruptions are preferentially found on expanded alleles in SCA8 families with increased disease penetrance and that age of onset is inversely correlated with the number of interruptions and not repeat length. Molecular studies in cell culture show CCG $\bullet$ CGG interruptions increase p-eIF $2 \alpha$, polyAla, and polySer RAN protein levels and the toxicity of the resulting arginine-interrupted polyGln expansion proteins. Our demonstration that $\mathrm{CCG} \bullet \mathrm{CGG}$ interruptions increase RAN protein levels and polyGln protein toxicity and are found in families with increased disease penetrance provides novel molecular insight into the variable penetrance and risk of developing SCA8.

\section{Results}

\section{Most SCA8 patients have no family history of ataxia}

To investigate the effects of sequence interruptions in SCA8, we performed a detailed genetic evaluation of expanded SCA8 alleles from a large cohort of SCA8 families $(n=77)$ including 199 expansion carriers ( $n=111$ affected, $n=88$ asymptomatic). Disease onset ranged from birth to 79 years with an average age of onset of 33.7 years (Table 1). Although the mutation is transmitted in an autosomal-dominant pattern, surprisingly 82\% (63/ 77) of these families had sporadic ataxia with no family history of disease, $5 \%(4 / 77)$ had family histories that appeared recessive, and only $13 \%$ (10/77) showed the expected autosomal-dominant inheritance pattern (Fig 1A). Interestingly, four of the sporadic and two familial cases are homozygous and have two expanded alleles. These data and previous reports of expansion alleles in unaffected family members and in the general population (Moseley et al, 2000a; Stevanin et al, 2000; Worth et al, 2000; Cellini et al, 2001; Ikeda et al, 2004; Zeman et al, 2004) highlight the need to understand the molecular basis of the variable penetrance found in SCA8.

Table 1. Repeat length is not a reliable predictor of SCA8 disease status.

\begin{tabular}{llll} 
& $\begin{array}{l}\text { Affected } \\
n=111\end{array}$ & $\begin{array}{l}\text { Asymptomatic } \\
n=88\end{array}$ & P-value \\
\hline Avg age onset (years) & $33.7 \pm 19.7$ & - & \\
\hline Females, $n$ (\%) & $57(51.35)$ & $49(55.68)$ & ns \\
\hline Males, $n$ (\%) & $54(48.65)$ & $39(44.32)$ & - \\
\hline Combined repeat \# & & & - \\
\hline Mean & $189 \pm 219.9$ & $188.5 \pm 211.1$ & ns \\
\hline Median & 113 & 98 & - \\
\hline Maximum & 1,455 & 1,000 & - \\
\hline Minimum & 54 & 52 &
\end{tabular}

Characteristics of participants are presented as mean \pm SD, number, and percentage of affected or asymptomatic individuals (\%). To determine group effect, Fisher's exact test was used for categorical variables and MannWhitney test for non-parametric continuous variables. Average age of onset (Avg age onset) $n=85$. ns: not significant. 

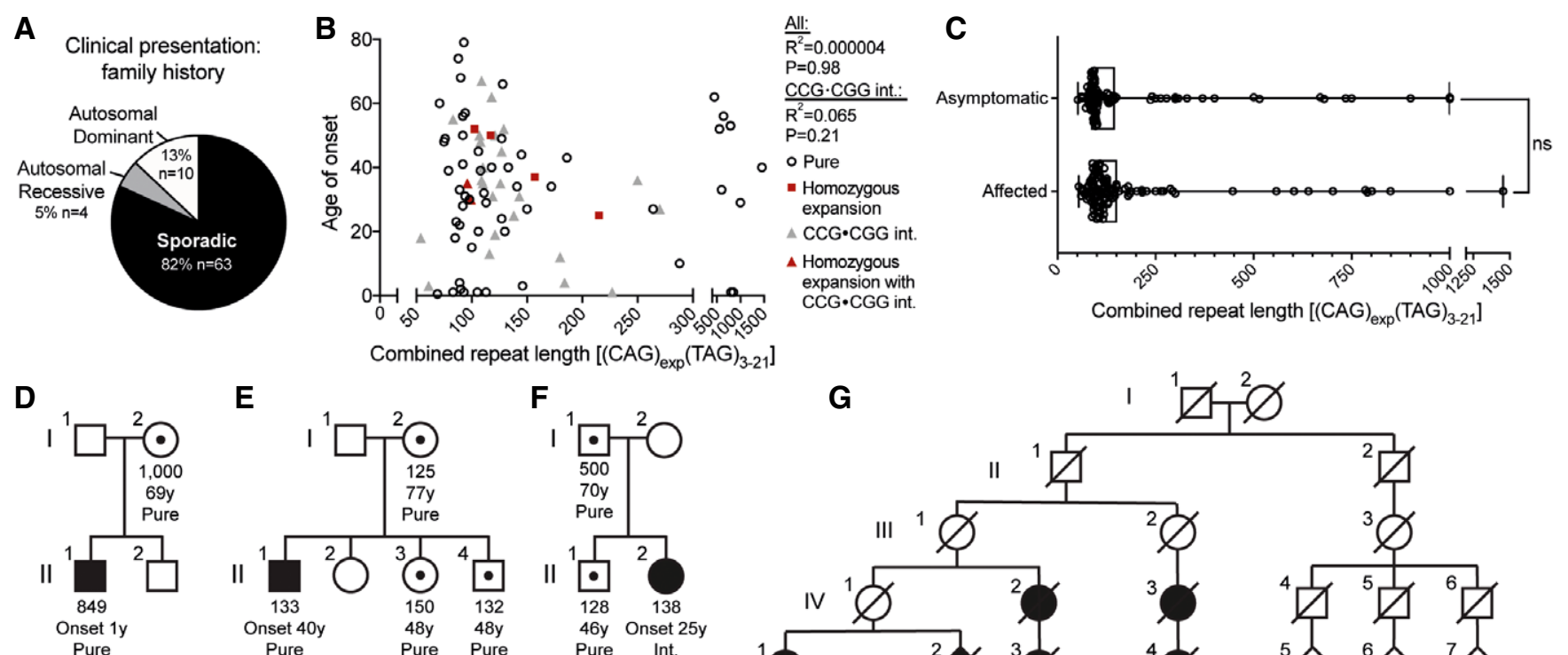

E
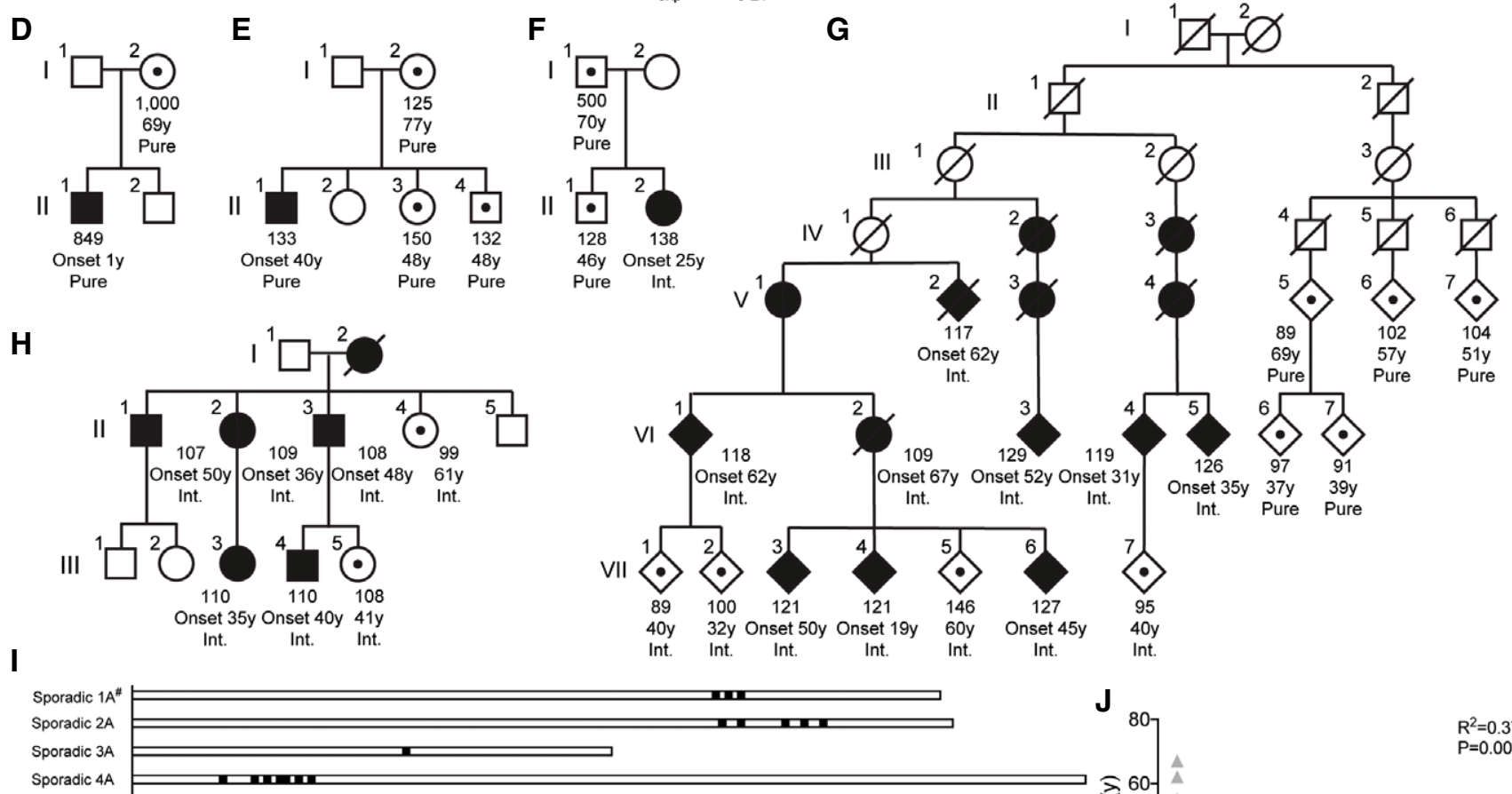

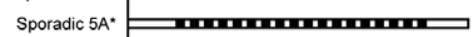

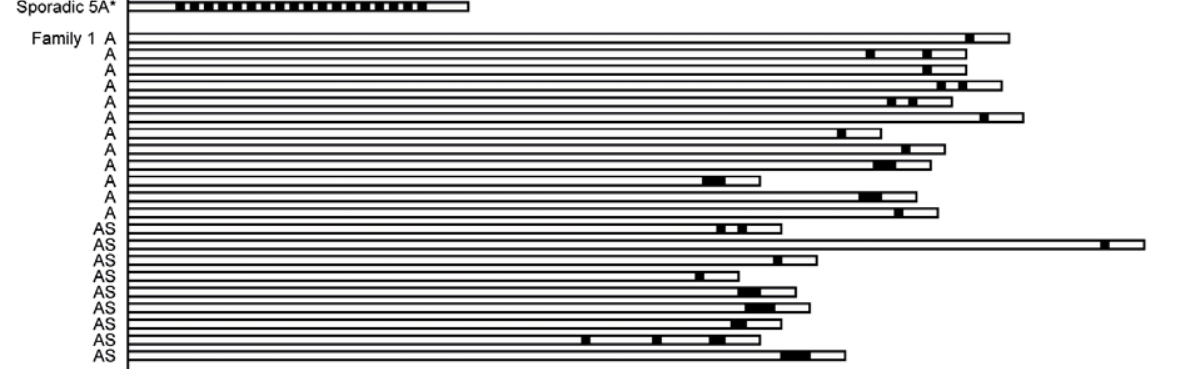

G

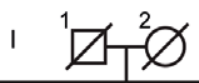
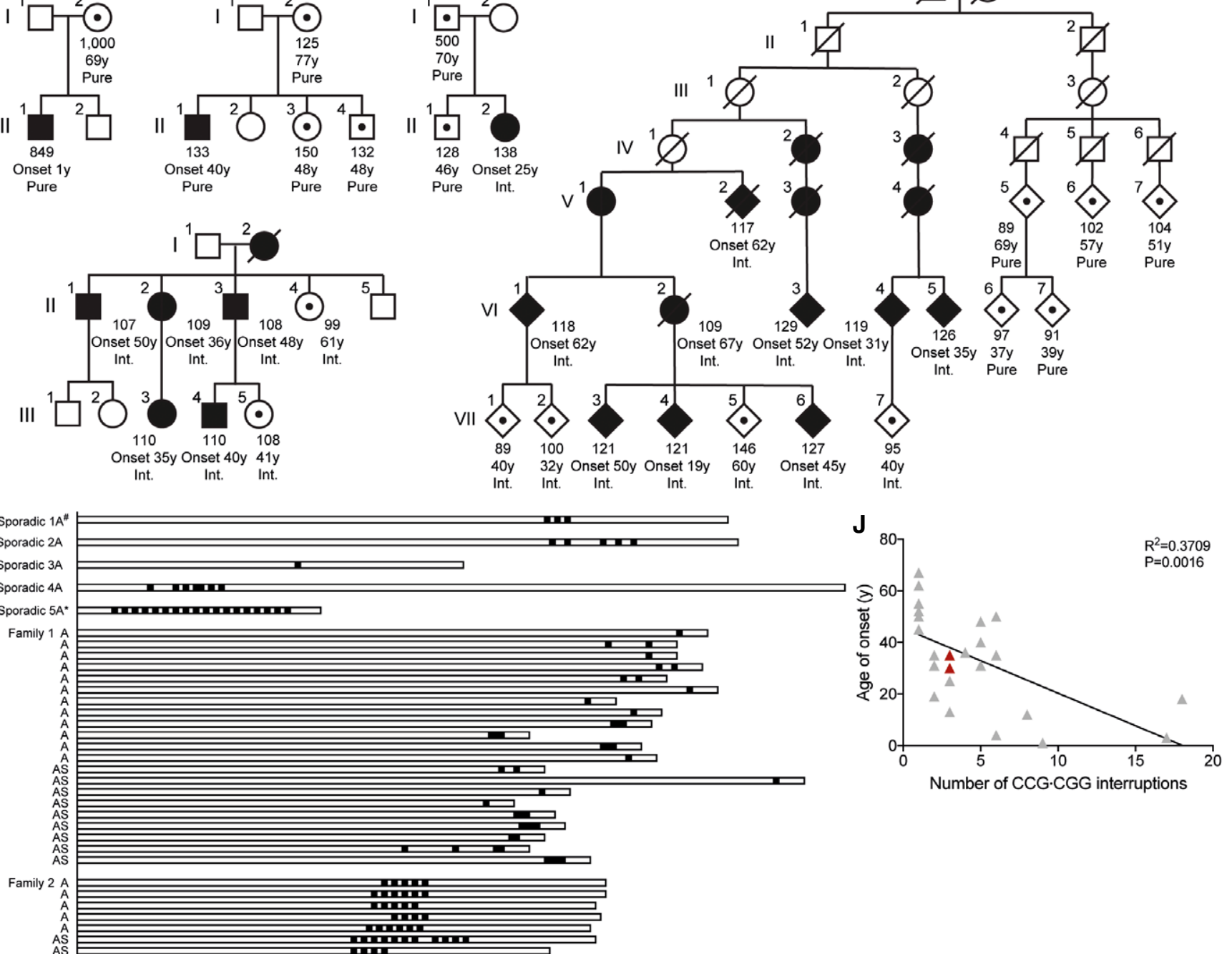

Family 3

Family 4

Family 5 A

Family $6 \underset{A}{A}=$

Family $7 \mathrm{~A}^{*}$ :mimimiming

:

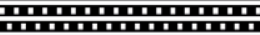

25

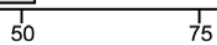

100

125

150

Repeat length of interrupted alleles

Figure 1. 
Figure 1. SCA8 alleles with CCG.CGG interruptions are found in families with high disease penetrance.

A Summary of disease history in the 77 SCA8 families in our cohort.

B No correlation between length of combined repeats and age of onset in SCA8 patients, $n=85, P=0.9847$ or in the subset of SCA8 patients with CCC.CGC interruptions (Int.), $n=26, P=0.2096$, linear regression analyses. Open circles indicate SCA8 patients with pure CAG repeat expansions. Red squares show average expansion size for individuals with two expanded alleles, individual allele repeat lengths: 137/177,110/320, 104/130, 96/109. Red triangles show average expansion size for individuals with two expanded alleles and CCG.CGG interruptions: 84/114, 92/100. Gray triangles indicate individuals with CCG.CGG interruptions.

C Allele length distribution of affected $(n=111)$ and asymptomatic $(n=88)$ expansion carriers; box: $25^{\text {th }}$ to $75^{\text {th }}$ percentile; whiskers: minimum to maximum value; $P=0.0672$, Mann-Whitney test.

D-H SCA8 family pedigrees: Squares represent males, circles represent females, and diamonds mask gender. Filled symbols represent affected individuals, symbols with dot represent asymptomatic expansion carriers, open symbols represent individuals with non-expanded alleles, and diagonal line indicates a deceased individual. Combined repeat number, age (y-years) at onset (Onset) or age still asymptomatic, and interruption status (Pure or Int. [CCG.CGG-interrupted]) are noted below the symbols. (C) Abbreviated pedigree, for additional details, see Koob et al (1999).

I SCA8 allele configurations in the CAG direction as determined by sequencing. Family or individual and affected status indicated on left: Sporadic 1-Fig 1F indicated by ", Family 1—Fig 1C, Family 2-Fig 1 H; A-affected, AS—Asymptomatic; CGC interruptions represented by black boxes. Sequences used in Fig $5 \mathrm{C}$ are indicated by *. See Appendix Table S1 for allele configurations.

J Age of onset correlates with the number of CCG.CCG interruptions, $n=24, P=0.0016$, linear regression analyses. Gray triangles indicate individuals with CCG.CGG interruptions. Red triangles indicate the average expansion size for individuals with two expanded alleles and CCG.CGG interruptions, and individual allele repeat lengths are as follows: 84/114, 92/100.

Data information: (I, J) Individuals identified as having CCG.CGG interruptions by restriction digest are not included.

\section{SCA8 repeat length does not correlate with age of onset or predict disease status}

Consistent with previous reports (Juvonen et al, 2000; Ikeda et al, 2004; Zeman et al, 2004; Cleary et al, 2021), we found: (i) no correlation in the number of SCA8 repeats and age of onset (Fig 1B); (ii) no significant difference in repeat length between affected patients (median: 113 repeats) and asymptomatic expansion carriers (median: 98 repeats; $P=0.0672$; Table 1 ); and (iii) a wide and overlapping range of repeat lengths in affected $(54-1,455)$ and asymptomatic expansion carriers (52-1,000; Fig 1C; Table 1). The lack of correlation between repeat length and disease status is often seen in individual SCA8 families. For example, in Fig 1D, individual I-2 carries an expansion of 1,000 repeats yet remains asymptomatic, while her son with 849 repeats presented with disease at 1 year of age. Similarly, in Fig 1E, individual II-1 presented with disease at age 40 with 133 combined repeats while his mother and two siblings, who carry SCA8 expansions of similar lengths, remain asymptomatic. Taken together, these data provide additional evidence that repeat length is not a reliable predictor of disease or age of onset and suggest other genetic or environmental modifiers contribute to the variable penetrance of SCA8.

A potential genetic modifier of SCA8 is the presence of interruptions within the CAG repeat expansion. In Fig 1F, a 25-year-old female (II-2), with no family history of SCA8, has an expansion mutation containing three de novo CGG interruptions [(CAG) $)_{91}(\mathrm{CAGCGG})_{3}(-$ $\mathrm{CAG})_{31}(\mathrm{TAG})_{10}$ ]. These interruptions were not present in her asymptomatic 70-year-old father (I-1; confirmed pure by MspA1I digest) or 46-year-old brother (II-1; (CAG) ${ }_{118}(\mathrm{TAG})_{10}$; Fig 1F). The observation that the only affected individual in this family has CCG•CGG interruptions, combined with the previously reported CCG $\bullet C G G$ interruptions in affected members of an unusually large SCA8 kindred (Moseley et $a l, 2000 \mathrm{~b})$, suggested to us that CCG•CGG interruptions are associated with increased disease penetrance.

\section{CCG.CGG interruptions increase disease penetrance and inversely correlate with age of onset}

To better understand the effects of CCG $\bullet$ CGG interruptions on disease penetrance, we compared the sequences of SCA8 expansion alleles in families with high ( $\geq 3$ affected) versus low disease penetrance. The seven-generation MN-A family (Koob et al, 1999; Day et al, 2000), the largest SCA8 family reported to date, has a much higher disease penetrance than most SCA8 families (Ikeda et $a l, 2004)$, and CCG•CGG interruptions were previously reported in all affected individuals (Moseley et al, 2000b). Additional analyses of this family show CCG•CGG interruptions are found in the high penetrance branch but not a newly identified low-penetrance branch of this family. The left family branch shows an autosomaldominant inheritance pattern (onset 19-74 years; Fig 1G) while members of the extended right branch have pure CTG $\bullet$ CAG expansions and no affected individuals (Fig 1G). In a second newly identified multigenerational family, all six affected individuals (onset 35-50 years; Fig $1 \mathrm{H}$ ) have CCG•CGG interruptions. These interruptions were also identified in individual II-4 who was not affected at the time of examination but subsequently showed signs of ataxia and in individual III-5 who was asymptomatic at age 41 (Fig 1H). CCG•CGG interruptions were found at a higher frequency in families with multiple affected individuals: $100 \%(5 / 5)$ of families with three or more affected individuals, $28.6 \%(2 / 7)$ of families with two affected individuals, and $13.9 \%$ $(5 / 36)$ of sporadic cases. Overall, CCG•CGG interruptions were found at a higher frequency in SCA8 families with two or more affected members compared with sporadic cases $(n=48$; $P=0.0047$; Table 2) and among affected individuals compared with asymptomatic carriers $(n=132 ; P=0.0299$; Table 2; Appendix Tables S1 and S2). While the position, configuration and number of $\mathrm{CCG} \bullet \mathrm{CGG}$ interruptions varies widely among SCA8 families (Fig 1I, Appendix Table S1), the number of CCG•CGG interruptions is inversely correlated with and accounts for $37 \%$ of the variation in age of onset $\left(R^{2}=0.3709\right.$; $P=0.0016$; Fig $\left.1 \mathrm{~J}\right)$. We saw no significant difference in changes in repeat length on paternal or maternal transmission of pure versus CCG $\bullet$ CGG-interrupted alleles (paternal transmission $P=0.5314$, maternal transmission $P=0.5748$; Fig EV1).

Taken together, these data demonstrate that CCG•CGG interruptions increase disease penetrance and that the number of interruptions, and not repeat length, is inversely correlated with age at onset in SCA8. 
Table 2. CGG interruptions are associated with increased disease penetrance in SCA8.

\begin{tabular}{|c|c|c|c|}
\hline Families & Pure & CGG interrupted & $P$-value \\
\hline Apparent sporadic & 31 (86\%) & $5(14 \%)$ & 0.0047 \\
\hline $2+$ affected & $5(42 \%)$ & $7(58 \%)$ & \\
\hline Individuals & Pure & CGG interrupted & P-value \\
\hline Affected & $41(55 \%)$ & $33(45 \%)$ & 0.0299 \\
\hline Asymptomatic & $43(74 \%)$ & $15(26 \%)$ & \\
\hline
\end{tabular}

$P$-values were calculated using Fisher's exact test to assess the relationship between disease penetrance and CGG interruptions ( $n=48$ families; $n=132$ expansion carriers) See Appendix Tables S1 and S2 for allele configurations. One family with CGG-interrupted alleles (Fig 1 I Family 4) contained a single GAG between the CAG expansion and the polymorphic TAG tract. An additional $n=10$ families, representing $n=19$ expansion carriers, were sequenced and found to carry different interruptions. The interruptions in these families included CTG, TAG, TGG, AAG, GAG, TAC, CCG (in the CAC direction) were not found in combination with CGG interruptions and were not included above; see Appendix Table S3 for all allele configurations.

\section{CCG.CGG interruptions increase the toxicity of SCA8 CTG.CAG repeat expansions}

To better understand the molecular effects of interrupted alleles, we tested whether constructs containing CCG•CGG interruptions are more toxic to cells than pure repeat expansion constructs. T98 glial cells were transfected with length-matched constructs containing pure or interrupted expansions cloned from patient DNA and expressed in the CAG direction (Fig 2A). Interrupted expansions were cloned from individuals from the high-penetrance multigeneration families shown in Fig 1G (Int.95) and Fig 1H (Int.102). Int.95 contains an overall CAG repeat length of 95 with four consecutive CGG interruptions near the $3^{\prime}$ end, followed by three TAGs $\left[(\mathrm{CAG})_{86}(\mathrm{CGG})_{4}(\mathrm{CAG})_{5}(\mathrm{TAG})_{3}\right]$. Int.102 contains four mixed CAGCGG interruptions in the middle of the CAG repeat for a total of 102 interrupted CAGs followed by six TAGs [(CAG) ${ }_{63}\left(\right.$ CGGCAG $_{4}(-$ $\left.\mathrm{CAG})_{31}(\mathrm{TAG})_{6}\right]$ (Fig 2A). Cells expressing these interrupted constructs showed increased death $(26.9 \%, P<0.05-$ Int.95 vs Pure 96; $23.5 \%, P<0.05$ - Int.102 vs Pure 104; Fig 2B) and decreased viability $(16.5 \%, P<0.05-$ Int.95 vs Pure 96; 15.6\%, $P<0.05$ - Int.102 vs Pure 104; Fig 2C) compared with lengthmatched uninterrupted repeats. These effects cannot be explained by differences in RNA levels which did not differ in Pure 96 versus Int.95-transfected cells and were lower in Int.102 vs Pure 104transfected cells (Fig 2D and E). Taken together, these data indicate that CGG interruptions increase the toxicity of CAG repeats independent of RNA levels.

\section{Arginine-encoding CGG interruptions increase toxicity of polyGIn proteins}

Next, we tested the hypothesis that CGG interruptions increase the toxicity of expanded alleles by affecting RAN and polyglutamine proteins expressed from the CAG repeat. First, we examined whether the arginine interruptions in the polyGln(Arg) proteins increase their toxicity compared with pure polyGln proteins. To perform these experiments, we generated minigene constructs to express polyGln and polyGln(Arg) using non-hairpin forming (RAN negative) alternative CAA or CAA/AGA-interrupted codons (Fig 3 A). This allowed us to test the toxicity of pure polyGln and interrupted polyGln(Arg) proteins individually and independent of possible effects from CAG expansion RNAs or RAN proteins. We focused these experiments on pure and interrupted polyGln proteins because non-hairpin forming alternative codons are available for both Gln and Arg. Transient transfections in T98 cells show that interrupted polyGln(Arg) proteins expressed with alternative codons increased cell death by $25 \%(P<0.05$; Fig $3 \mathrm{~B})$ and decreased cell viability by $10 \%$ compared with pure polyGln proteins $(P<0.05$; Fig $3 \mathrm{C})$, independent of RNA levels (Fig 3D).

Protein lysates from HEK293T cells overexpressing polyGln(Arg)interrupted proteins from alternative codon constructs show polyGln (Arg) proteins migrate further into protein gels than the pure polyGln proteins (Fig EV2A). The change in mobility is likely caused by the introduction of positively charged arginine interruptions in these polar uncharged polyglutamine proteins. Similar results were found in HEK293T cells transfected with CAG repeat constructs (Fig 3E), with quantification showing substantially less soluble interrupted polyGln(Arg) compared with soluble pure polyGln (Fig $3 \mathrm{~F}$ and G). Dot blots of insoluble protein fractions from HEK293T cells transfected with CAG repeat constructs do not show significant differences in pure polyGln versus polyGln(Arg) levels (Fig EV2B-E).

To further examine the effects of the arginine interruptions, HEK293T cells were transfected with pure and interrupted CAG repeat containing constructs and examined by immunofluorescence (IF). PolyGln(Arg)-interrupted proteins showed droplet-like nuclear staining not found in cells expressing pure polyGln proteins (Fig $3 \mathrm{H}$ ). Similarly, in HEK293T cells transfected with CAA- or CAA/AGAinterrupted constructs, $73 \%$ of cells overexpressing polyGln(Arg) proteins have one or more intranuclear droplet-like inclusions $(P<0.0001$; Fig $3 \mathrm{I}$ and $\mathrm{J})$, which are only rarely $(>1 \%)$ found in cells overexpressing pure polyGln proteins (Fig 3J). These inclusions, which are found in transfected HEK293T and HeLa cells, colocalize with the nucleolar marker nucleophosmin (Figs 3K and EV2F).

Taken together, these data demonstrate that arginine interruptions promote the formation of droplet-like nucleolar inclusions and increase the toxicity of polyGln expansion proteins independent of possible CAG RNA gain-of-function or RAN protein effects.

\section{CGG interruptions increase polyAla and polySer RAN protein levels}

Next, we examined the effects of the CGG interruptions on the two other repetitive proteins encoded by the CAG expansion transcripts, polySer and polyAla RAN proteins. Transient transfections with interrupted and pure repeat constructs show CGG interruptions substantially increase steady-state levels of polySer and polyAla RAN proteins (Fig 4). In the polySer reading frame, the GGC interruptions produce a polySer protein with glycine interruptions, polySer(Gly). Both pure polySer and polySer(Gly) proteins are highly insoluble with no protein detected in the soluble fraction (Fig EV3A). Dot blot analyses of the insoluble protein fraction showed 93.8\% higher levels of interrupted RAN polySer(Gly) compared with pure RAN polySer proteins $(P<0.01$; Fig $4 \mathrm{~A}$ and $\mathrm{B})$. Transfections with constructs containing interspersed CGG interruptions (Int.102) showed $85.1 \%$ higher levels of RAN polySer(Gly) compared with pure RAN polySer proteins (Pure 104; $P<0.05$; Fig 4A and $C$ ). 


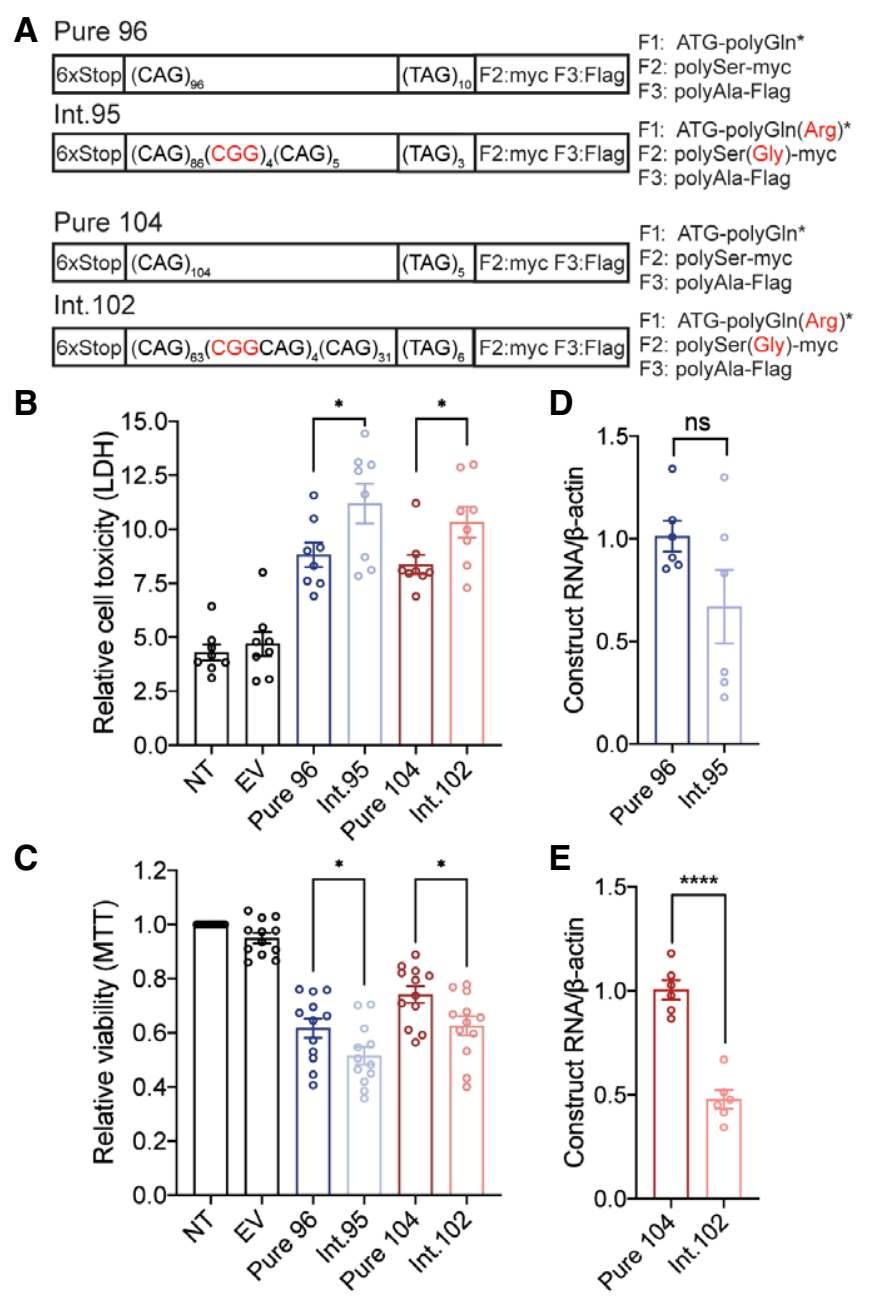

Figure 2. Clustered and interspersed CCG.CGG interruptions increase toxicity of CTG.CAG expansions.

A Schematic diagram of constructs used to express patient-derived pure and interrupted SCA8 repeat tracts with predicted protein products and C-terminal epitope tags. * Due to TAG encoded stop codons, polyCln proteins do not express an epitope tag. CGG interruptions and the encoded amino acid interruptions are indicated in red.

B, C Cell death measured by lactase dehydrogenase (LDH) (B) and cell viability measured by 3-(4,5-dimethyl-thiazol-. 2-yl)-2,5-diphenyl tetrazolium bromide (MTT) (C) in T98 cells 42 hrs post-transfection of pure and interrupted SCA8 repeat tracts; $\mathrm{LDH} n=8, \mathrm{MTT} n=12, n=$ independent experiments, ${ }^{*} P<0.05$, NT: not transfected, EV: empty vector; unpaired $t$-test; mean \pm SEM.

D, E RT-qPCR showing transcript levels of Pure 96 and Int.95 (D, $n=6$; $P=0.0187)$, and Pure 104 and Int.102 $\left(E, n=6 ;{ }^{* \star * \star} P<0.0001\right)$ repeats; $n=$ independent experiments; unpaired $t$-test; mean \pm SEM.

Similarly, immunofluorescence showed RAN polySer(Gly) proteins form globular or clustered aggregates compared with punctate aggregates formed by pure polySer RAN proteins (Fig 4D). Additionally, total aggregate burden is greater in cells expressing polySer (Arg) compared with pure polySer $(P<0.01$ for each experiment; Fig 4E).

Protein blots showed even higher increases (7.8-fold) in steadystate levels of polyAla RAN proteins expressed from interrupted (Int. 95) compared with pure (Pure 96) CAG repeats $(P<0.001$;
Fig $4 \mathrm{~F}$ and G). Transfections with constructs containing interspersed CGG interruptions (Int. 102) showed similar polyAla increases (2.8fold) compared with size comparable pure repeats (Pure 104; $P<0.01$; Fig EV3B and C). The increases in polyAla protein levels did not result in overt changes in cellular localization (Fig EV3D) and were found in both soluble and insoluble protein fractions (Fig EV3F). The increases in polyAla and polyser RAN protein levels expressed from interrupted repeats were not caused by differences in RNA levels (Figs 4H and EV3E).

Additionally, we show in transiently transfected HEK293T cells that overexpression of interrupted repeats activated the integrated stress response (ISR) and increased p-eIF $2 \alpha$ levels by $49 \%$ compared with pure repeats $(P<0.05$, Fig $4 \mathrm{I}$ and $\mathrm{J})$.

Taken together, these data show CGG interruptions increase steady-state levels of polySer and polyAla RAN proteins and activate the ISR independent of RNA levels. Additionally, the fact that pure polyAla proteins are expressed from both interrupted and pure CAG expansions indicates that the increase in steady-state levels of polyAla RAN proteins is not caused by changes in protein composition that could affect the stability of the polyAla protein.

\section{CGG interruptions increase stability of CAG expansion transcript secondary structure}

RAN translation is favored by repeat length and RNA structure (Zu et al, 2011, 2013; Banez-Coronel et al, 2015; Wang et al, 2019), and RNA hairpin stability is known to increase with repeat length (Napierala et al, 2005; Wang et al, 2019). CGG interruptions increase the steady-state levels of polyAla without altering the amino acid sequence, suggesting that the increased levels of RAN proteins expressed from interrupted alleles are caused by changes in RNA structure or stability. Consistent with this hypothesis, UV melting analyses of RNA oligos with CGG interruptions required higher melting temperatures than oligos with pure repeats (Figs 5A and EV4). Additionally, computational predictions using $m$-fold (Zuker, 2003) of short RNAs show increased stability with the presence of CGG interruptions (Figs 5B and EV5A). Next, we examined the stability of interrupted alleles found in patients. We used $m$-fold to compare the stability of several highly interrupted full-length CAG repeat tracts from patients (48-53 repeats), with length-matched pure repeats. Results from these studies show that the multiple predicted hairpin structures, including branched structures, are more stable for alleles containing CGG-interrupted CAG repeats compared with length-matched pure CAGs (Figs 5C and EV5B). Both the number and configuration of the interruptions influence RNA structural stability in computational (Fig 5B) and UV melting (Fig 5A) analyses. Taken together, these data are consistent with a model in which increased stability of the secondary structures of CGG-interrupted expansion transcripts increases RAN translation.

\section{Discussion}

The markedly reduced penetrance is one of the most puzzling features of SCA8 (Koob et al, 1999; Stevanin et al, 2000; Worth et al, 2000; Ikeda et al, 2004). Here, we show that $82 \%$ of SCA 8 families in a large cohort have only a single affected individual, even though the repeat expansion mutation is inherited in an autosomal- 
A

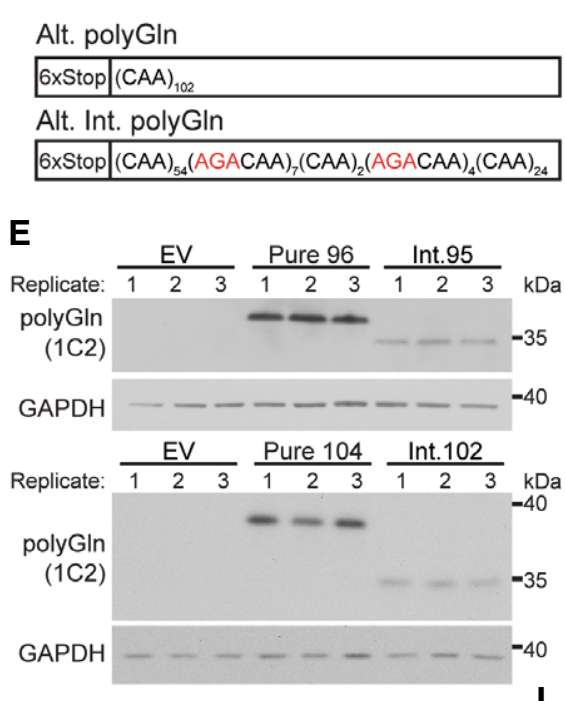
ATG-polyGIn

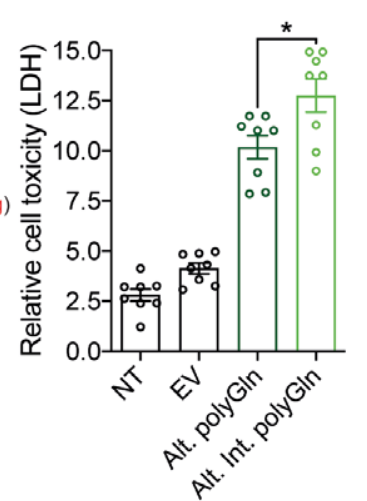

H
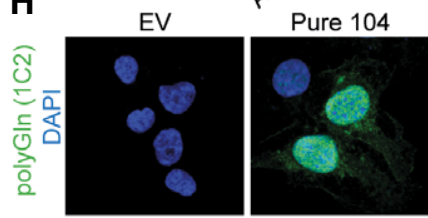

C

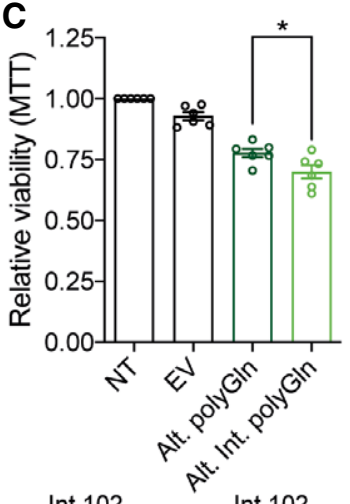

D

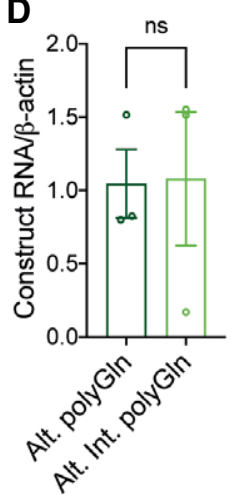

F

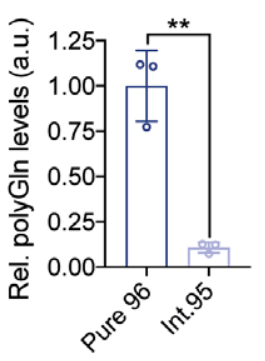

G

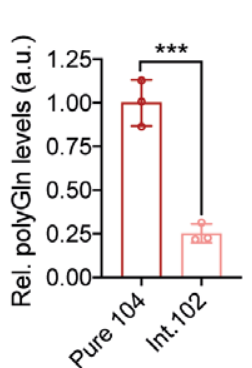

J

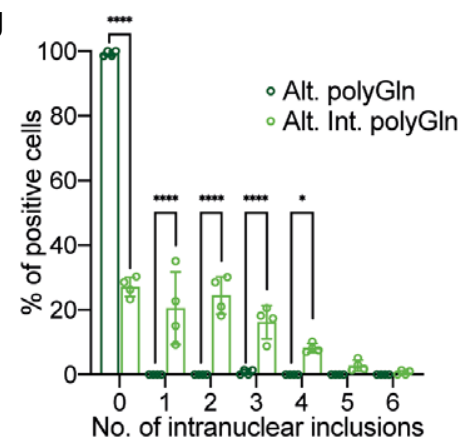

1 Al novisin
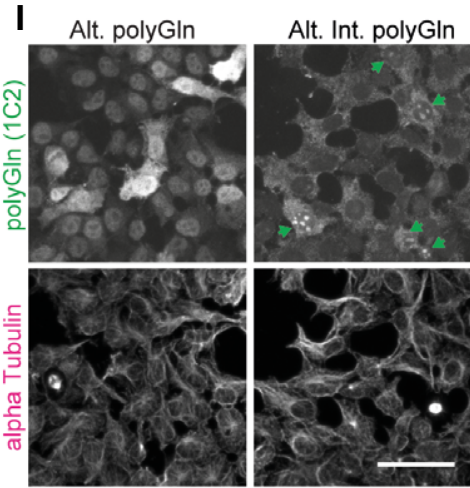

K K EV
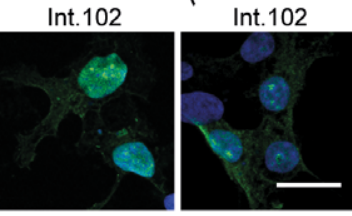

EV
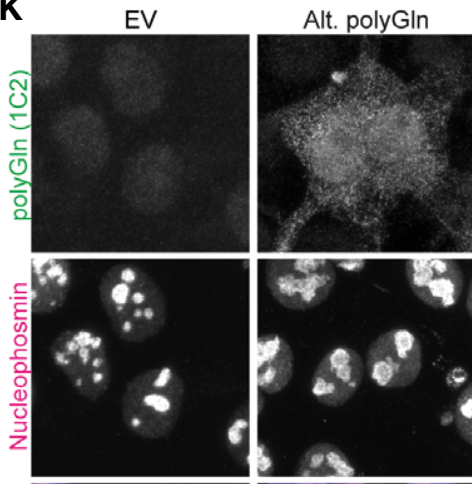

Alt. Int. polyGIn
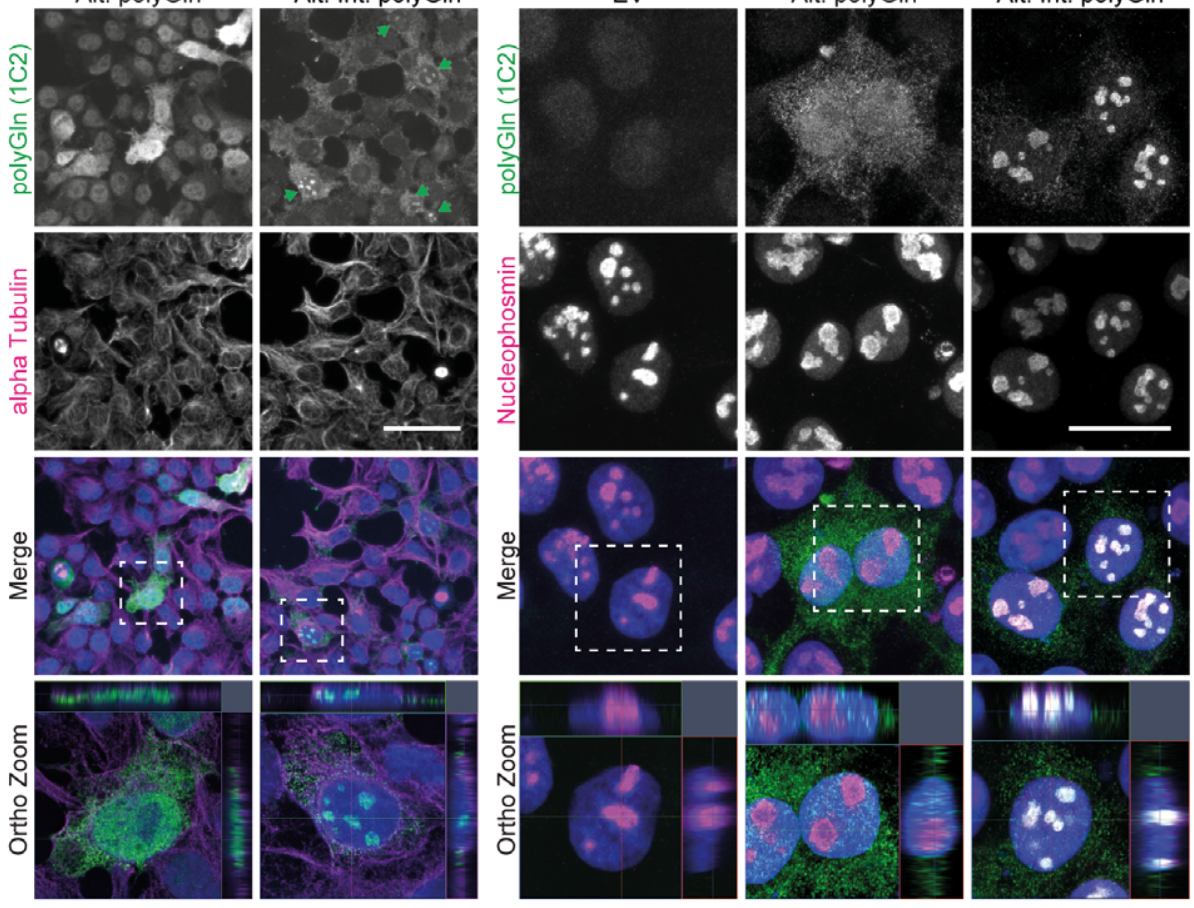

Figure 3. Arginine interruptions increase toxicity of ATXN8 polyGln proteins.

A Alternative-codon constructs for pure and interrupted polyGln assays.

$\mathrm{B}, \mathrm{C}$ Cell death (B; LDH, $n=8)$ and viability (C; MTT, $n=6)$ assays in T98 cells $42 \mathrm{~h}$ post-transfection. NT: not transfected; EV: empty vector; $n=$ independent experiments; ${ }^{*} P<0.05$; unpaired $t$-test; mean \pm SEM.

D RT-qPCR of Alt. polyGIn and Alt. Int. polyGIn construct transcript levels, $n=3$ independent experiments; $P=0.9516$, ns: not significant, unpaired $t$-test, mean \pm SEM.

E-G Protein blots $(E)$ and quantification $(F, G)$ of polyGIn proteins expressed in transfected HEK293T cells with interrupted or pure polyCln repeats; EV: empty vector; $n=3$ transfections, ${ }^{* *} P<0.01,{ }^{\star * *} P<0.001$, unpaired $t$-test, mean \pm SD.

$\mathrm{H} \quad$ Immunofluorescence of polyGIn expressed from Pure 104 and Int.102 constructs in HEK293T cells; scale bar: $20 \mu \mathrm{m}$; EV: empty vector.

I, J Immunofluorescence (I) and quantification (J) of intranuclear inclusions for polyGIn expressed from Alt. polyGIn and Alt. Int. polyGIn constructs in HEK293T cells; scale bar: $50 \mu \mathrm{m}$; green arrowheads indicate cells positive for Alt. Int. polyGIn intranuclear inclusions; dashed white box in merge panels indicates the region shown in the orthogonal (Ortho) zoomed images which show cross section and localization of diffuse polyGIn staining and nuclear polyGIn(Arg) inclusions with alphatubulin as a cytoplasmic marker; $n=4$ experiments with $n>55$ cells per experiment, ${ }^{\star} P<0.05$, ${ }^{\star * \star *} P<0.0001$, two-way ANOVA, data presented as mean percentage of polyGIn-positive cells \pm SD.

K PolyGIn(Arg) proteins but not pure polyGIn proteins colocalize with nucleophosmin in HEK293T cells; scale bars: $20 \mu$ m; dashed white box in merge panels indicates the region shown as an orthogonal projection in the Ortho zoom panels which show the co-localization of polycln inclusions and nucleophosmin in three dimensions.

Source data are available online for this figure. 
A

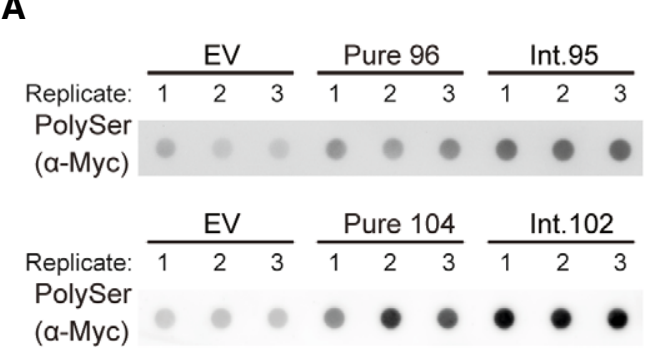

B

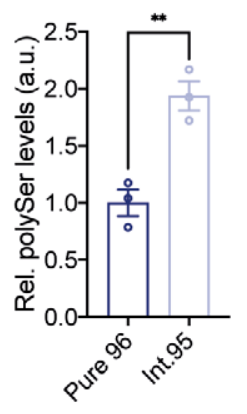

C

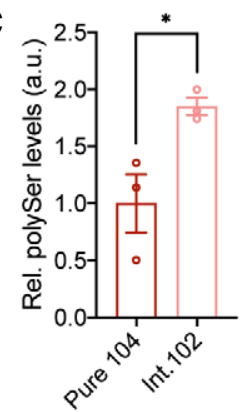

D

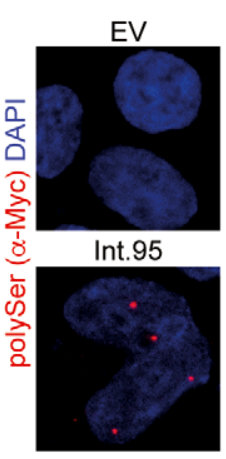

E

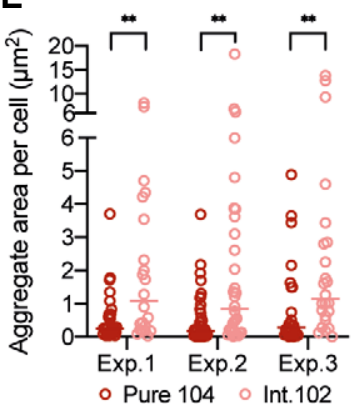

Pure 96

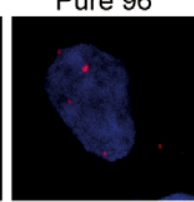

Int.95

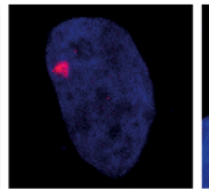

$\mathbf{G}$

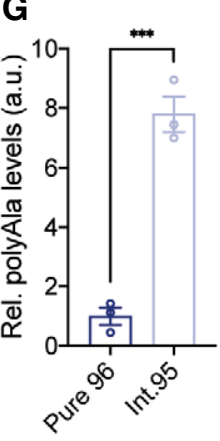

Pure 104

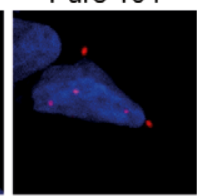

Int.102

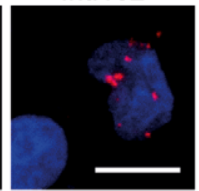

$\mathbf{F}$

Replicate:

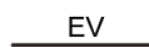

Pure $96 \quad$ Int.95
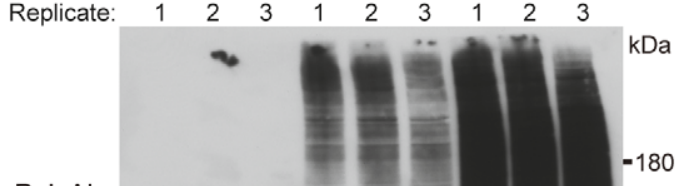

PolyAla

(a-Flag)

(a-Flag)

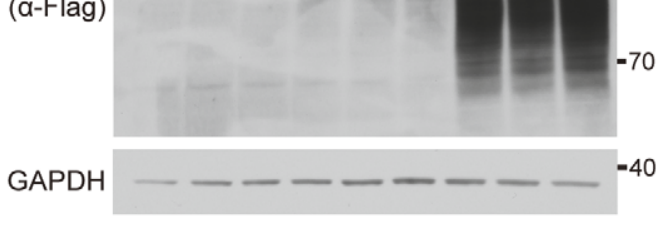

I

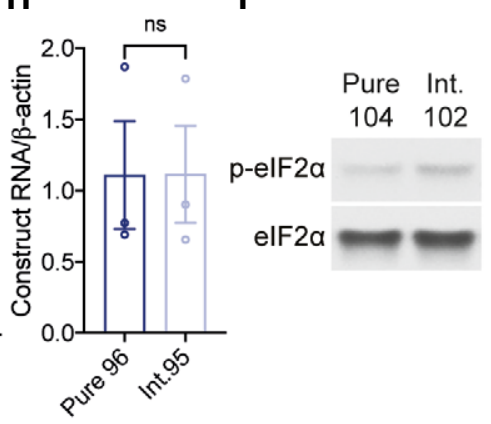

J

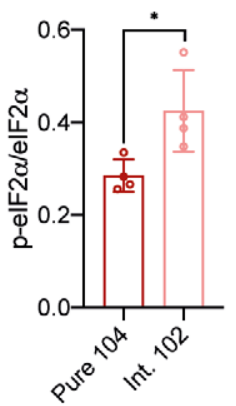

Figure 4. CGG interruptions increase RAN polySer and RAN polyAla protein steady-state levels.

A-C Protein blotting (A) and quantification (B, C) of polySer RAN proteins in HEK293T cells from interrupted (Int.95; Int.102) or pure (Pure 96; Pure 104) CAC repeats. EV: empty vector, $n=3$ transfections, ${ }^{* *} P<0.01$, ${ }^{*} P<0.05$, unpaired $t$-test, mean \pm SEM.

$D, E$ Immunofluorescence (D) and quantification (E) of RAN polySer protein aggregates from CGG-interrupted and pure CAG repeat tracts in HEK293T cells; scale bar: $10 \mu \mathrm{m} . n>20$ cells per construct for each experiment (Exp.), ${ }^{\star *} P<0.01$ : Exp.1 $P=0.0073$, Exp. $2 P=0.0017$, Exp.3 $P=0.0041$, Mann-Whitney test; data presented as individual points with median.

F, G Protein blot (F) and quantification (G) of polyAla RAN proteins expressed from pure or interrupted constructs; $n=3$ transfections, ${ }^{\star \star \star} P<0.001$, unpaired $t$-test, mean \pm SD.

H RT-qPCR of Pure 96 and Int.95 transcript levels; $n=3$ transfections; $P=0.9942$, unpaired $t$-test, mean \pm SEM.

I, J Protein blotting (I) and quantification (J) of phospho-elF2 $\alpha$ (p-elF2 $\alpha$ ) relative to total elF2 $\alpha ; n=4$ transfections, ${ }^{*} P<0.05$, unpaired $t$-test, mean \pm SD.

Source data are available online for this figure.

dominant manner. A much smaller percentage of families $(13 \%)$ showed the expected autosomal-dominant pattern of disease. $\mathrm{CCG} \bullet \mathrm{CGG}$ interruptions in the $\mathrm{CTG} \bullet \mathrm{CAG}$ repeat tract are found at a higher frequency in families with multiple affected individuals and that the number of $\mathrm{CCG} \bullet \mathrm{CGG}$ interruptions, and not repeat length, correlates with age at onset. Cell culture studies show CAG expansions with CGG interruptions are more toxic than pure repeats. At the protein level, CGG interruptions within the CAG repeat tract increase steady-state levels of the SCA8 RAN polyAla and polySer proteins. This observation is consistent with the increased stability of RNA structures predicted on CGG-interrupted alleles and the elevated p-eIF $2 \alpha$ levels. It will be interesting in future work to test whether the elevated p-eIF $2 \alpha$ levels are caused by PKR activation, which can be activated by structured microsatellite RNAs (Edery et al, 1989; Tian et al, 2000; Zu et al, 2020) and which has been recently shown to be a major driver of RAN translation ( $\mathrm{Zu}$ et al, 2020) or result from feedforward effects in which the RAN proteins activate the integrated stress response and p-eIF $2 \alpha$, which further increases RAN translation (Green et al, 2017; Cheng et al, 2018; Sonobe et al, 2018; Zu et al, 2020; Tusi et al, 2021). Additionally, 
A

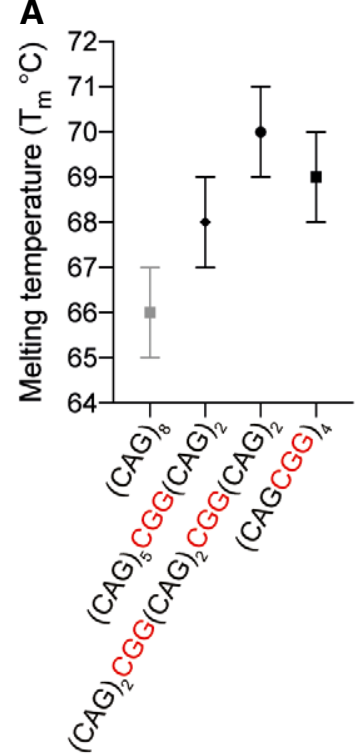

B

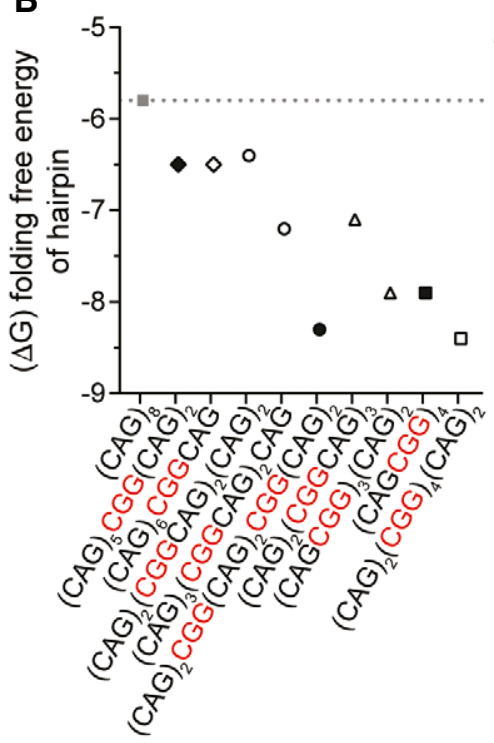

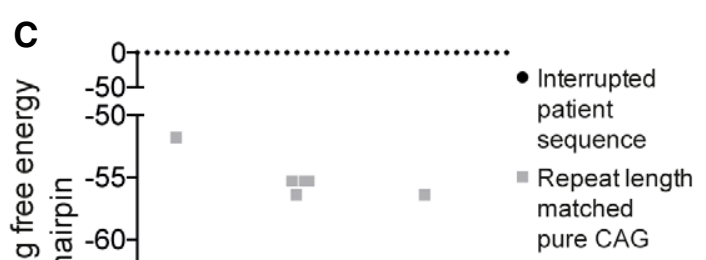

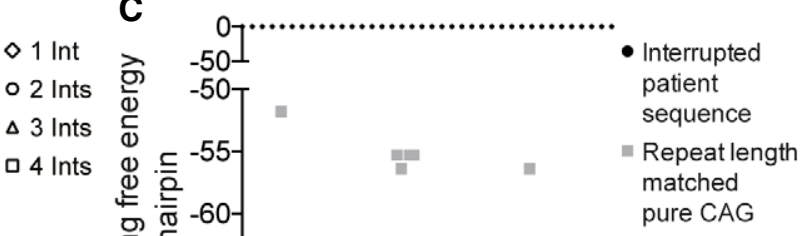

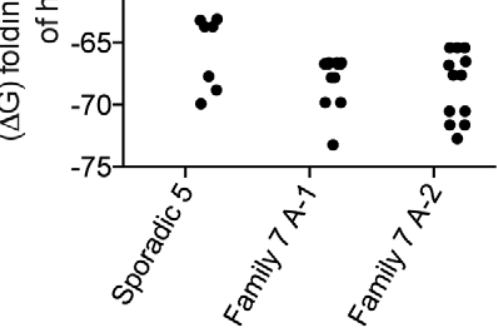

Figure 5. CGG interruptions increase stability of CAG repeat RNA hairpins.

A Absorbance of each RNA substrate at $260 \mathrm{~nm}$ monitored between 25 and $95^{\circ} \mathrm{C}$, recorded at $1^{\circ} \mathrm{C}$ intervals; $n=3$ UV melting curves per RNA substrate (technical replicates), mean \pm SD.

B The $\mathrm{m}$-fold (Zuker, 2003) predicted folding free energy $(\Delta G)$ of hairpin structures of pure CAC and CGG-interrupted repeat tracts with different configurations. Filled symbols show sequences also used for UV melting analyses. Gray dotted line indicates $\Delta G$ of pure $(C A C)_{8}$.

C The folding free energy $(\Delta G)$ of interrupted hairpin structures of repeat expansions found in SCA8 patients (Fig 11$)$ and pure repeat tracts of the same length, as predicted by $\mathrm{m}$-fold. Patient-derived alleles are as follows: Sporadic 5-48 repeats in length-(CAC) ${ }_{7}(\mathrm{CGCCAC})_{18}(\mathrm{CAC})_{5}$; Family 7 A-1-53 repeats in length$(\mathrm{CAC})_{8}(\mathrm{CGGCAG})_{14}(\mathrm{CAC})_{2} \mathrm{CGG}(\mathrm{CAG})_{5} \mathrm{CGG}(\mathrm{CAC})_{8}$; and Family $7 \mathrm{~A}-2-52$ repeats in length-(CAG) $)_{7}(\mathrm{CGGCAG})_{16}(\mathrm{CAC})_{4} \mathrm{CGG}(\mathrm{CAC})_{8}$. Each symbol represents a single predicted hairpin structure; multiple hairpin structures, including branched hairpins, are predicted for each SCA8 patient allele and for pure (CAG) $)_{53}$ (Zuker, 2003). Black dotted line shows $\Delta G=0$.

CGG interruptions introduce arginine amino acids into the polyGln proteins which increases their toxicity. Taken together, these data demonstrate that CCG $\bullet$ CGG interruptions act as cis-modifiers of SCA8 and provide a molecular explanation for the dramatic variations in disease penetrance among SCA8 families.

We found CCG•CGG interruptions on expanded alleles in all families in our cohort with three or more cases of SCA8. CCG•CGG interruptions were also identified in sporadic SCA8 cases, but at a lower frequency. Additionally, we confirm that repeat length in SCA8 is a poor predictor of disease penetrance (Stevanin et al, 2000; Worth et al, 2000; Ikeda et al, 2004). Taken together, these data indicate that the inclusion of sequence information during genetic testing, specifically the presence or absence of CCG•CGG interruptions, will provide patients and families with additional information relevant to disease penetrance. For asymptomatic SCA8 expansion carriers, the risk of developing ataxia is increased by the presence of CCG $\bullet$ CGG interruptions, which more frequently occur in families with a prior history of ataxia. However, SCA8 ataxia patients may or may not have a family history of disease or sequence interruptions (Table 3). Sequence analyses will also further our understanding of the role of additional types of interruptions on disease penetrance in SCA8 and help identify the causes of high penetrance in other large SCA8 families in the literature for which the expansion sequences are unknown (Cintra et al, 2017). Additionally, we have identified SCA8 patients with shorter repeat expansions than have been previously reported, expanding the range of repeats found in individuals affected with ataxia to 54-1,455 repeats.
Table 3. Lifetime risk of developing SCA8.

\begin{tabular}{l|lll}
\multicolumn{2}{l}{ ATXN8OS/ATXN8 genotype } & \\
\cline { 1 - 2 } $\begin{array}{l}\text { CTG.CAG } \\
\text { expansion }\end{array}$ & $\begin{array}{l}\text { + CCG.CGG } \\
\text { interruptions }\end{array}$ & $\begin{array}{l}\text { Ataxia } \\
\text { symptoms }\end{array}$ & $\begin{array}{l}\text { Lifetime risk } \\
\text { of developing SCA8 }\end{array}$ \\
\hline+ & - & - & At risk \\
\hline+ & + & - & Increased risk \\
\hline+ & $+/-$ & + & SCA8 \\
\hline
\end{tabular}

A CTC.CAG expansion in ATXN8OS/ATXN8 is sufficient to put an individual at risk for developing SCA8. For asymptomatic SCA8 expansion carriers, the risk of developing ataxia is increased by the presence of CCG.CGG interruptions, which more frequently occur in families with a prior history of ataxia The presence or absence of interruptions would not influence a diagnosis of SCA8 in patients with ataxia symptoms and SCA8 CTG.CAG expansions, including diagnosis of sporadic SCA8 cases.

Here, we show that polyGln(Arg)-interrupted proteins are more toxic than pure polyGln proteins and that steady-state levels of RAN polyAla and polySer proteins expressed from interrupted repeats are increased. This increase in toxicity caused by CCG•CGG interruptions could be sufficient to tip the balance of cellular homeostasis to degeneration and cell death in cells sensitive to the SCA8 repeat expansion. Taken together, it is possible that CCG•CGG interruptions in SCA8 patients increase overall cellular toxicity and RAN protein load which may in turn exacerbate the associated pathologies, including white matter defects (Ayhan et al, 2018), in SCA8. 
While the data presented here provide insight into possible molecular consequences of the CCG•CGG interruptions in SCA8 repeat expansions, further detailed analyses in patient cell lines and postmortem tissue will be necessary to fully understand the pathological consequences of the CCG•CGG interruptions. Additionally, while the current SCA8-BAC mouse model carries CCG•CGG interruptions, development of an isogenic SCA8 expansion mouse model without $\mathrm{CCG} \bullet \mathrm{CGG}$ interruptions would be valuable to further investigate the role of CCG $\bullet$ CGG interruptions on disease in SCA8. Directly comparing tissues and cell lines from SCA8 patients or animal models with pure and CCG•CGG-interrupted repeat expansions would also improve our understanding of the contribution of repeat expansion proteins to disease.

RAN translation has now been described in 11 microsatellite expansion diseases and in several of these diseases the differences between RAN proteins that contain arginine residues and those that do not have been characterized. For example, in myotonic dystrophy type 2 (DM2), RAN translation across the sense CCTG repeat produces polyLPAC proteins which show a diffuse cytoplasmic distribution in HEK293T cells but RAN translation across the antisense CAGG repeat produces polyQAGR proteins which form droplet-like nuclear staining not found with polyLPAC proteins ( $\mathrm{Zu}$ et al, 2017). Similarly, in C9orf72 ALS/FTD, polyGR and polyPR form droplet-like nuclear structures that colocalize with nucleolar markers while polyGA, polyGP, and polyPA show diffuse nuclear and cytoplasmic localization (Wen et al, 2014; Tao et al, 2015). Furthermore, the arginine containing polyGR and polyPR proteins are more toxic in cell culture and Drosophila than the dipeptide repeat proteins that do not contain arginine residues (Mizielinska et al, 2014; Wen et al, 2014; Tao et al, 2015; Lee et al, 2016) and they have been shown to impair ribosomal RNA biogenesis, perturb stress granule dynamics and biomolecular phase separation, and induce nucleolar stress (Kwon et al, 2014; Tao et al, 2015; Lee et al, 2016; Boeynaems et al, 2017; White et al, 2019). Similar to the polyGR and polyPR proteins found in C9orf72 ALS/FTD, the SCA8 arginine-interrupted polyGln(Arg) proteins show increased toxicity and droplet-like nucleolar inclusions. These striking molecular parallels between SCA8, DM2, and C9orf72 ALS/FTD suggest similar molecular mechanisms are at play and that the effects of polyGln (Arg) proteins on nucleolar stress and stress granule dynamics warrant further investigation.

There is a growing body of evidence that structured RNAs, including RNA hairpins, favor efficient RAN translation (Zu et al, 2011; Banez-Coronel et al, 2015; Wang et al, 2019). RAN translation has also been shown to be more efficient with longer repeat lengths, and longer repeats increase the stability of RNA secondary structures (Napierala et al, 2005; Zu et al, 2011, 2013; Banez-Coronel et al, 2015; Wang et al, 2019; Pattamatta et al, 2020). Our data extend these results and show that CGG interruptions, which increase the stability of RNA hairpins, also lead to elevated levels of RAN proteins and show that increasing RNA stability without altering repeat tract length increases RAN translation. Additionally, the increased stability of RNA secondary structures containing CGG interruptions could also lead to increased toxicity through RNA gain-of-function mechanisms (Daughters et al, 2009) possibly by the changes in the sequestration of known or novel RNA binding proteins by SCA8 expansion transcripts.

While additional types of AT-rich sequence interruptions (e.g., $\mathrm{CTT} \bullet \mathrm{AAG}, \mathrm{CCA} \bullet \mathrm{TGG}, \mathrm{CTA} \bullet \mathrm{TAG})$ have been reported in SCA8
(Moseley et al, 2000b; Hu et al, 2017), the lack of highly penetrant SCA8 families with AT-rich interruptions (Moseley et al, 2000b) makes it unlikely that they increase disease penetrance in a manner similar to CGG interruptions. This is consistent with the prediction that AT-rich interruptions decrease RNA structural stability of CAG expansion transcripts in contrast to CGGs, which increase RNA secondary structure stability. A small number of sporadic cases are homozygous for the expansions, suggesting the presence of two SCA8 expansion alleles may also increase disease penetrance (Fig 1 B). The fact that SCA8 is also found with reduced penetrance in patients with single uninterrupted expansion mutations suggests that, similar to other neurodegenerative diseases, trans-genetic modifiers and environmental factors are also likely to contribute to disease (Mo et al, 2015; Hosseinibarkooie et al, 2017).

In summary, CCG•CGG interruptions within the SCA8 CAG repeat tract are associated with increased penetrance in SCA8 families. At the molecular level, CCG•CGG interruptions increase RNA stability and levels of polyAla and polySer RAN proteins. Additionally, CCG•CGG interruptions encode alternative amino acids that increase the toxicity and change the molecular properties of the resulting polyGln(Arg) proteins. Taken together, these data provide novel insight into the molecular mechanisms affecting disease penetrance in SCA8.

\section{Materials and Methods}

\section{Research participants}

Informed consent was acquired from all participants in accordance with the Human Subjects Committee at the University of Minnesota, the Institutional Review Board (IRB) at the University of Florida, or the equivalent office at collaborators' institutions. The experiments conformed to the principles set out in the WMA Declaration of Helsinki and the Department of Health and Human Services Belmont Report. A board-certified neurologist identified SCA8 probands on clinical examination, and interested patients were enrolled into the research study. Family history of ataxia was assessed by questionnaire, and patients were encouraged to inform affected and unaffected relatives of the research study; volunteers were enrolled into the study. SCA8 families were included in our study if the repeat length and gender of the proband were known. Patients for whom repeat size could not be determined or DNA was not available were not included in the study. Samples were collected from 77 independent families.

\section{Genetic analysis of SCA8 repeat expansions}

Genomic DNA (gDNA) was extracted from peripheral blood lymphocytes using FlexiGene DNA Kit (Qiagen). The number of combined $\mathrm{CTG} \bullet \mathrm{CAG} / \mathrm{CTA} \bullet \mathrm{TAG}$ repeats at the SCA8 locus was determined by PCR across the repeat using CAG-1F (5' TTT GAG AAA GGC TTG TGA GGA $3^{\prime}$ ) and CAG-1R (5' TCT GTT GGC TGA AGC CCT AT $3^{\prime}$ ) primers. PCR bands were extracted using Wizard SV Gel and PCR Clean-Up System (Promega) and, when possible, sent for direct DNA sequencing using nested primers CAG-3F $\left(5^{\prime}\right.$ GGC TTG TGA GGA CTG AGA ATG 3') and CAG-3R (5' GAA GCC CTA TTC CCA ATT CC $3^{\prime}$ ). Expansions too large for direct sequence 
(approximately $>250$ repeats) were digested with MspA1I (New England Biolabs) which ambiguously digests the PCR products containing either CGG or CTG interruptions in the CAG direction of the repeat tract. This method confirms the presence of CGG interruptions but does not provide the sequence configuration. If the expansion size was too large to perform PCR across the repeat, the repeat length was estimated by Southern blot. Families found to have non-CGG interruptions were excluded from analysis of CGG interruptions and disease penetrance.

\section{cDNA constructs}

To generate patient-derived pure and interrupted SCA8 expansion constructs (Pure 104, Int.102, Pure 96, Int.95) for molecular characterization of CGG interruptions, a region containing the ATXN8 open reading frame was PCR amplified from patients' gDNA using primers SCA8-F3-Kpn1 (5' TTG GTA CCT TTG AGA AAG GCT TGT GAG GAC TGA GAA TG 3') and SCA8-R4-EcoRI (5' GCG AAT TCG GTC CTT CAT GTT AGA AAA CCT GGC T $3^{\prime}$ ). The PCR fragment was cloned in the CAG direction into the pcDNA3.1-6xStop-triple tag (pcDNA3.1-6S-3T) vector which has a six stop cassette (two stop codons per reading frame) upstream of the repeat and a unique Cterminal tag in each reading frame ( $\mathrm{Zu}$ et al, 2011). The pcDNA3.16S-3T construct was used as the empty vector for all studies. Due to the TAG repeat tract encoding for multiple stop codons after the CAG repeat stretch, there is no C-terminal tag in the CAG frame. Construct names (Pure 104, Int.102, Pure 96, Int.95) denote the total CAG tract length which, due to repeat instability during cloning, may not be the same total tract length as the patient alleles used to clone the repeat sequences.

To assess polyGln proteins in the insoluble fraction, the CAG expansion constructs were re-cloned without the TAG repeat tract (GenScript) to generate HA-tagged polyGln proteins which can be detected by a HA-tag antibody. While the repeat configuration is identical between the constructs with and without the TAG codons, due to repeat instability during cloning, the repeat tract length may not be identical (Fig EV2B).

To assess toxicity of polyGln proteins, ATG-initiated non-hairpin forming alternative codon minigenes were synthesized by IDT Technologies and subcloned into the pcDNA3.1-6S-3T vector. PolyGln is encoded by CAA repeats with AGA-encoded Arginine interruptions to generate the Alt. polyGln and Alt. Int. polyGln constructs (Fig 3 A). It is not possible to model polyAla or polySer proteins using this system as no non-hairpin forming alternative codons exist for alanine or glycine.

\section{Cell culture and transfections}

HEK293T, T98, or HeLa cells were cultured in DMEM (Corning) supplemented with $10 \%$ fetal bovine serum (Gibco) and 1X penicillin-streptomycin (Gibco). Plasmid transfections were performed using Lipofectamine 2000 (Invitrogen) according to the manufacturer's instructions. Plasmid transfection amounts were optimized for each set of constructs used for toxicity assays. For polyGln IF analyses, $4 \times 10^{4}$ cells were seeded per well of a poly-D-lysine/ laminin coated eight-well culture slide (Corning) and transfected with $150 \mathrm{ng}$ construct DNA using $0.25 \mu \mathrm{l}$ Lipofectamine 2000 per well.

\section{Toxicity and viability assays}

Cell toxicity and viability were assessed in T98 cells $42 \mathrm{~h}$ posttransfection using the CytoTox 96 Nonradioactive Cytotoxicity Assay (Promega) or 3-(4,5-dimethyl-thiazol-2-yl)-2,5-diphenyl tetrazolium bromide (MTT) assay (Sigma), respectively, following the manufacturer's protocol. Briefly, total LDH release was measured by lysing the cells with $1 \%$ Triton X-100 and absorbance was measured at $490 \mathrm{~nm}$. MTT was added to cell culture media at a final concentration of $0.5 \mathrm{mg} / \mathrm{ml}$ and incubated for $45 \mathrm{~min}$ at $37^{\circ} \mathrm{C}$. Following media removal cells were lysed with $100 \mu \mathrm{l}$ of dimethyl sulfoxide (DMSO; Fisher Scientific), and absorbance was measured at $595 \mathrm{~nm}$. Toxicity and viability assays were performed in a minimum of six independent experiments, and in each independent experiment, the assays were performed in quintuplet.

\section{RNA extraction and RT-qPCR}

RNA was isolated from transiently transfected HEK293T or T98 cells using TRIzol Reagent (Invitrogen). RNA was DNase treated using TURBO DNA-free Kit (Ambion), following the manufacturer's instructions. cDNA was synthesized using random hexamer primers and the SuperScript III Reverse Transcriptase System (Invitrogen) following the manufacturer's protocol. Quantification of construct transcript levels was performed using the 5'FLAG (5' GAT TAC AAG GAC GAC GAC GAC $3^{\prime}$ ) and 3'HIS (5' ATG GTG ATG GTG ATG ATG ACC $3^{\prime}$ ) primers. Control reactions were performed using human $\beta$ actin forward ( $5^{\prime}$ TCG TGC GTG ACA TTA AGG AG $3^{\prime}$ ) and human $\beta$-actin reverse ( $5^{\prime}$ GAT CTT CAT TGT GCT GGG TG $3^{\prime}$ ) primers. For each biological replicate, three technical replicates were performed for qPCR. RT-qPCR results were analyzed using the $2^{-\Delta \Delta C T}$ method (Livak \& Schmittgen, 2001).

\section{Immunoblotting}

HEK293T cells were washed with 1xPBS 48 h post-transfection and were lysed in $200 \mu$ radioimmunoprecipitation assay (RIPA) buffer (Thermo Scientific) with $1 \mathrm{X}$ cOmplete Protease Inhibitors (Roche) for $15 \mathrm{~min}$ on ice. DNA was sheared by passage through a 21gauge needle, lysates were centrifuged at $21,000 \mathrm{~g}$ for $15 \mathrm{~min}$ at $4^{\circ} \mathrm{C}$, and the supernatant was collected. The protein lysate concentration was quantified using Pierce BCA Protein Assay Kit (Thermo Scientific), and $10 \mu \mathrm{g}$ of soluble protein lysates was separated on a $4-12 \%$ Bis-Tris gel (Bio-Rad) and transferred to a nitrocellulose membrane. The remaining insoluble protein pellet was extracted in $2 \%$ SDS in RIPA buffer by incubating at $42^{\circ} \mathrm{C}$ for $3 \mathrm{~h}$ with frequent repeated pipetting, incubated at room temperature overnight, centrifuged at 21,000 $\mathrm{g}$ for $15 \mathrm{~min}$ at room temperature, and the supernatant was collected. Insoluble protein lysate was passed through a Dot Blot Apparatus (Bio-Rad) onto a PVDF membrane. Membranes were blocked for $2 \mathrm{~h}$ at room temperature in $5 \%$ dry milk in 1xPBS containing $0.05 \%$ Tween-20 (Sigma) and probed with anti-FLAG antibody (Abcam, Cat. \# ab1162, 1:2,000), antimyc antibody (Abcam, Cat. \# ab9106, 1:1,000), anti-HA antibody (BioLegend, Cat. \# 901501, clone 16B12, 1:2,000), 1C2 antibody (Millipore, Cat. \# MAB1574, 1:10,000), rabbit anti-EIF2S1 (phospho-S51; Abcam, Cat. \# ab32157, 1:1,000), mouse anti-eIF2 $\alpha$ (Santa Cruz, sc-133227, 1:2,000), and anti-GAPDH antibody 
(Millipore, Cat. \# MAB374, 1:5,000) overnight at $4^{\circ} \mathrm{C}$ in blocking solution. The membrane was incubated with species-specific HRPconjugated secondary antibody (Amersham) in blocking solution, and bands were visualized with the ECL plus Western Blotting Detection System (Amersham). Quantification of protein expression was performed using ImageJ. For dot blot quantification antibody signal for empty vector transfections was used to perform background reduction. All protein levels are normalized to pure repeat expansion protein levels.

\section{Immunofluorescence}

HEK293T and HeLa cells were fixed 48 h post-transfection (for RAN polyAla and RAN polySer) or $24 \mathrm{~h}$ post-transfection (for polyGln) with $4 \%$ paraformaldehyde (PFA; Electron Microscopy Sciences) in $1 \times$ PBS for $15 \mathrm{~min}$ and permeabilized with $0.5 \%$ Triton X-100 (Sigma) in $1 \times$ PBS for $30 \mathrm{~min}$. Cells were blocked in $1 \%$ normal goat serum (NGS) for $30 \mathrm{~min}$ and incubated overnight at $4^{\circ} \mathrm{C}$ with 1C2 antibody (Millipore, Cat. \# MAB1574, 1:10,000), nucleophosmin antibody (Abcam, Cat. \# ab183340, 1:500), alpha-tubulin (Abcam, Cat. \# ab52866, 1:500), or anti-FLAG antibody (Abcam, Cat. \# ab1162, 1:1,000), or for $1 \mathrm{~h}$ at $37^{\circ} \mathrm{C}$ with anti-myc antibody (Abcam, Cat. \# ab9106, 1:1,000). Cells were incubated with AlexaFluor-conjugated secondary antibodies (1:300) for $1 \mathrm{~h}$ at room temperature and were mounted with ProLong Gold Antifade (Thermo Scientific). Representative images were taken using the LSM 880 (ZEISS) confocal microscope with an AiryScan module. Images for quantification were taken using the LSM 880 (ZEISS) confocal microscope using consistent settings between experiments. For analysis of polyGln intranuclear inclusions, 1C2 staining was used to determine whether cells were positive for polyGln proteins, and then, the number of intranuclear inclusions was quantified. Analysis of polySer RNA protein aggregates was performed in ImageJ using the MaxEntropy threshold followed by the Smooth, Make Binary, and Analyze Particles functions.

\section{UV melting}

RNA oligonucleotides were purchased from IDT. Absorbance of each RNA substrate at $260 \mathrm{~nm}$ was monitored between 25 and $95^{\circ} \mathrm{C}$, recorded at $1^{\circ} \mathrm{C}$ intervals. Three UV melting curves were generated per RNA substrate at a concentration of $2 \mu \mathrm{M}$ in 1 xDPBS without calcium or magnesium.

\section{Statistical analysis}

All statistical analyses were performed using GraphPad Prism 6.0 software. The D'Agostino and Pearson normality test or Shapiro-Wilk normality test were used to assess normal distribution and statistical tests for which the data meet the assumptions of the tests were selected. Statistical relationship of CCG•CGG interruptions and disease penetrance was calculated using Fisher's exact test. Linear regression analyses were performed to assess the relationship between age of onset and repeat length or interruption number. All other statistical analyses were performed using an unpaired twotailed $t$-test or a two-way ANOVA for parametric data or the MannWhitney test for non-parametric data, as appropriate. Investigators were blinded for all quantification of immunofluorescent data. All cell

\section{The paper explained}

Problem

Spinocerebellar ataxia type 8 (SCA8) is unusual because most individuals that carry the CTC.CAC repeat expansion mutation do not develop ataxia.

Results

Using a large SCA8 patient cohort, we demonstrate that CCG.CGG interruptions in the SCA8 CTG.CAC repeat expansion are associated with increased penetrance of disease and account for $37 \%$ of the variation in age of onset in SCA8 patients with interrupted alleles. At the molecular level, CCG.CGG-interrupted CTG.CAG repeat expansions are more toxic to cells than pure CTC.CAG repeat expansions and lead to increased steady-state levels of polyAla and polySer proteins produced through repeat-associated non-AUG (RAN) translation.

\section{Impact}

Our study shows the number of CCG.CGG interruptions is correlated with increased disease penetrance and decreased age of onset in SCA8 patients. CGG-interrupted ATXN8 CAG expansions are more toxic to cells than pure repeats. These interruptions increase RNA stability, activate the integrated stress response, and increase polyAla and polyser RAN protein levels and the toxicity of the resulting arginineinterrupted polyGln proteins. These data provide novel molecular insight into the variable penetrance of SCA8 and the risk of developing the disease.

culture experiments were performed with a minimum of 3 biological replicates; the variation in cell-based systems was consistent across multiple transfections. Randomization was not applicable to this study as samples were not assigned to groups. Data are reported as mean $\pm \mathrm{SEM}$, mean $\pm \mathrm{SD}$, individual values, or median.

\section{Data availability}

This study includes no data deposited in public repositories. All data is available in the source files or appendix.

Expanded View for this article is available online.

\section{Acknowledgements}

We thank study participants and their families for participating in our study. We thank Dr. M. Swanson, Dr. J.D. Cleary, and members of the Ranum lab for helpful suggestions. This work was funded by NIH R37 NS040389 (L.P.W.R.), a T32 training grant NS082168 (B.A.P.), and the National Ataxia Foundation. The graphical abstract was created with BioRender.com.

\section{Author contributions}

BAP, HKS, YI, and LPWR designed the project. HKS, BAP, MB-C, LELR, TZ, TR, LAL, KR, and YI conducted experiments. HKS, BAP, YI, MB-C, KR, and JAB analyzed data. SHS, CMG, TA, TB, AB, LJS, LFH, JEN, and LPWR provided patient DNA samples and collected clinical information. HKS, BAP, and LPWR wrote the manuscript with input from all the authors.

\section{Conflict of interests}

Tao $\mathrm{Zu}$ and Laura Ranum are inventors on patents and pending patents on RAN translation and/or SCA8. 


\section{For more information}

https://neurogenetics.med.ufl.edu/faculty/dr-laura-p-w-ranum/

https://www.ataxia.org/fact-sheets/

https://www.omim.org/entry/608768

https://www.ncbi.nlm.nih.gov/books/NBK1268/

\section{References}

Ayhan F, Perez BA, Shorrock HK, Zu T, Banez-Coronel M, Reid T, Furuya H, Clark HB, Troncoso JC, Ross CA et al (2018) SCA8 RAN polySer protein preferentially accumulates in white matter regions and is regulated by elF3F. EMBO J 37: e99023

Bañez-Coronel M, Ayhan F, Tarabochia A, Zu T, Perez B, Tusi S, Pletnikova O, Borchelt D, Ross C, Margolis R et al (2015) RAN translation in huntington disease. Neuron 88: 667-677

Banez-Coronel M, Ranum LPW (2019) Repeat-associated non-AUG (RAN) translation: insights from pathology. Lab Invest 99: 929-942

Boeynaems S, Bogaert E, Kovacs D, Konijnenberg A, Timmerman E, Volkov A, Guharoy M, De Decker M, Jaspers T, Ryan VH et al (2017) Phase separation of C9orf72 dipeptide repeats perturbs stress granule dynamics. Mol Cell 65 1044-1055.e1045

Braida C, Stefanatos RKA, Adam B, Mahajan N, Smeets HJM, Niel F, Goizet C, Arveiler B, Koenig M, Lagier-Tourenne C et al (2010) Variant CCG and CGC repeats within the CTC expansion dramatically modify mutational dynamics and likely contribute toward unusual symptoms in some myotonic dystrophy type 1 patients. Hum Mol Genet 19: 1399-1412

Buijsen RA, Visser JA, Kramer P, Severijnen EA, Gearing M, Charlet-Berguerand $\mathrm{N}$, Sherman SL, Berman RF, Willemsen R, Hukema RK (2016) Presence of inclusions positive for polyglycine containing protein, FMRpolyG, indicates that repeat-associated non-AUG translation plays a role in fragile $X$ associated primary ovarian insufficiency. Hum Reprod 31: 158-168

Cellini E, Nacmias B, Forleo P, Piacentini S, Guarnieri BM, Serio A, Calabro A, Renzi D, Sorbi S (2001) Genetic and clinical analysis of spinocerebellar ataxia type 8 repeat expansion in Italy. Arch Neurol 58: 1856-1859

Cheng W, Wang S, Mestre AA, Fu C, Makarem A, Xian F, Hayes LR, LopezGonzalez R, Drenner K, Jiang J et al (2018) C9ORF72 GGGGCC repeatassociated non-AUC translation is upregulated by stress through elF2alpha phosphorylation. Nat Commun 9: 51

Chung MY, Ranum LP, Duvick LA, Servadio A, Zoghbi HY, Orr HT (1993) Evidence for a mechanism predisposing to intergenerational CAG repeat instability in spinocerebellar ataxia type I. Nat Genet 5: 254-258

Cintra VP, Lourenco CM, Rocha MMV, Tomaselli PJ, Marques Jr W (2017) Analysis of a fully penetrant spinocerebellar ataxia type 8 Brazilian family. Acta Neurol Scand 136: 541-545

Cleary JD, Pattamatta A, Ranum LPW (2018) Repeat-associated non-ATC (RAN) translation. J Biol Chem 293: 16127-16141

Cleary JD, Subramony SH, Ranum LPW (2021) Spinocerebellar ataxia type 8. In GeneReviews ${ }^{\circledR}$ ), Adam MP, Ardinger HH, Pagon RA, Wallace SE, Bean LJH, Mirzaa G, Amemiya A (eds). Seattle, WA

Daughters RS, Tuttle DL, Gao W, Ikeda Y, Moseley ML, Ebner TJ, Swanson MS, Ranum LP (2009) RNA gain-of-function in spinocerebellar ataxia type 8. PLoS Genet 5: e1000600

Day JW, Schut LJ, Moseley ML, Durand AC, Ranum LP (2000) Spinocerebellar ataxia type 8: clinical features in a large family. Neurology 55: 649-657

Edery I, Petryshyn R, Sonenberg N (1989) Activation of double-stranded RNAdependent kinase (dsl) by the TAR region of HIV-1 mRNA: a novel translational control mechanism. Cell 56: 303-312
Felling RJ, Barron TF (2005) Early onset of ataxia in a child with a pathogenic SCA8 allele. Pediatr Neurol 33: 136-138

Genetic Modifiers of Huntington's Disease C (2019) CAG repeat not polyglutamine length determines timing of Huntington's disease onset. Cell 178: 887-900.e814

Goodman LD, Bonini NM (2019) Repeat-associated non-AUG (RAN) translation mechanisms are running into focus for GGCCCC-repeat associated ALS/FTD. Prog Neurogibol 183: 101697

Green KM, Clineburg MR, Kearse MG, Flores BN, Linsalata AE, Fedak SJ, Goldstrohm AC, Barmada SJ, Todd PK (2017) RAN translation at C9orf72associated repeat expansions is selectively enhanced by the integrated stress response. Nat Commun 8: 2005

Gunter C, Paradee W, Crawford DC, Meadows KA, Newman J, Kunst CB, Nelson DL, Schwartz C, Murray A, Macpherson JN et al (1998) Reexamination of factors associated with expansion of CGG repeats using a single nucleotide polymorphism in FMR1. Hum Mol Genet 7: 1935-1946

Hosseinibarkooie S, Schneider S, Wirth B (2017) Advances in understanding the role of disease-associated proteins in spinal muscular atrophy. Expert Reu Proteomics 14: 581-592

Hu Y, Hashimoto Y, Ishii T, Rayle M, Soga K, Sato N, Okita M, Higashi M, Ozaki K, Mizusawa $\mathrm{H}$ et al (2017) Sequence configuration of spinocerebellar ataxia type 8 repeat expansions in a Japanese cohort of 797 ataxia subjects. J Neurol Sci 382: 87-90

Ikeda Y, Shizuka M, Watanabe M, Okamoto K, Shoji M (2000) Molecular and clinical analyses of spinocerebellar ataxia type 8 in Japan. Neurology 54: 950-955

Ikeda Y, Dalton JC, Moseley ML, Gardner KL, Bird TD, Ashizawa T, Seltzer WK, Pandolfo M, Milunsky A, Potter NT et al (2004) Spinocerebellar ataxia type 8: molecular genetic comparisons and haplotype analysis of 37 families with ataxia. Am J Hum Genet 75: 3-16

Imbert G, Saudou F, Yvert G, Devys D, Trottier Y, Garnier J-M, Weber C, Mandel J-L, Cancel G, Abbas $N$ et al (1996) Cloning of the gene for spinocerebellar ataxia 2 reveals a locus with high sensitivity to expanded CAG/glutamine repeats. Nat Genet 14: 285-291

Ishiguro T, Sato N, Ueyama M, Fujikake N, Sellier C, Kanegami A, Tokuda E, Zamiri B, Gall-Duncan T, Mirceta M et al (2017) Regulatory role of RNA chaperone TDP-43 for RNA misfolding and repeat-associated translation in SCA31. Neuron 94: 108-124.e7

Juvonen V, Hietala M, Paivarinta M, Rantamaki M, Hakamies L, Kaakkola S, Vierimaa O, Penttinen M, Savontaus ML (2000) Clinical and genetic findings in Finnish ataxia patients with the spinocerebellar ataxia 8 repeat expansion. Ann Neurol 48: 354-361

Kim JS, Son TO, Youn J, Ki CS, Cho JW (2013) Non-Ataxic phenotypes of SCA8 mimicking amyotrophic lateral sclerosis and parkinson disease. J Clin Neurol 9: 274-279

Koob MD, Moseley ML, Schut LJ, Benzow KA, Bird TD, Day JW, Ranum LP (1999) An untranslated CTC expansion causes a novel form of spinocerebellar ataxia (SCA8). Nat Genet 21: 379-384

Koutsis G, Karadima G, Pandraud A, Sweeney MG, Paudel R, Houlden H, Wood NW, Panas M (2012) Genetic screening of Greek patients with Huntington's disease phenocopies identifies an SCA8 expansion. J Neurol 259: $1874-1878$

Kunst CB, Warren ST (1994) Cryptic and polar variation of the fragile $X$ repeat could result in predisposing normal alleles. Cell 77: 853-861

Kwon I, Xiang S, Kato M, Wu L, Theodoropoulos P, Wang T, Kim J, Yun J, Xie Y, McKnight SL (2014) Poly-dipeptides encoded by the C9orf72 repeats bind nucleoli, impede RNA biogenesis, and kill cells. Science 345: 11391145 
Lee K-H, Zhang P, Kim HJ, Mitrea DM, Sarkar M, Freibaum BD, Cika J, Coughlin M, Messing J, Molliex A et al (2016) C9orf72 dipeptide repeats impair the assembly, dynamics, and function of membrane-less organelles. Cell 167: 774-788.e717

Lilja A, Hamalainen P, Kaitaranta E, Rinne R (2005) Cognitive impairment in spinocerebellar ataxia type 8. J Neurol Sci 237: 31-38

Livak KJ, Schmittgen TD (2001) Analysis of relative gene expression data using real-time quantitative PCR and the 2(-delta delta $C(T))$ method. Methods 25: $402-408$

McEachin ZT, Gendron TF, Raj N, García-Murias M, Banerjee A, Purcell RH, Ward PJ, Todd TW, Merritt-Garza ME, Jansen-West K et al (2020) Chimeric peptide species contribute to divergent dipeptide repeat pathology in C9ALS/FTD and SCA36. Neuron 107: 292-305.e296

McFarland KN, Liu J, Landrian I, Zeng D, Raskin S, Moscovich M, Gatto EM, Ochoa A, Teive HAG, Rasmussen A et al (2014) Repeat interruptions in spinocerebellar ataxia type 10 expansions are strongly associated with epileptic seizures. Neurogenetics 15: 59-64

Mizielinska S, Gronke S, Niccoli T, Ridler CE, Clayton EL, Devoy A, Moens T, Norona FE, Woollacott IOC, Pietrzyk J et al (2014) C9orf72 repeat expansions cause neurodegeneration in Drosophila through arginine-rich proteins. Science 345: 1192-1194

Mo C, Hannan AJ, Renoir T (2015) Environmental factors as modulators of neurodegeneration: insights from gene-environment interactions in Huntington's disease. Neurosci Biobehav Rev 52: 178-192

Mori K, Weng S-M, Arzberger T, May S, Rentzsch K, Kremmer E, Schmid B, Kretzschmar HA, Cruts M, Van Broeckhoven C et al (2013) The C9orf72 GGGGCC repeat is translated into aggregating dipeptide-repeat proteins in FTLD/ALS. Science 339: 1335-1338

Moseley ML, Schut LJ, Bird TD, Day JW, Ranum LP (2000a) Reply. Nat Genet 24: 215

Moseley ML, Schut LJ, Bird TD, Koob MD, Day JW, Ranum LP (2000b) SCA8 CTC repeat: en masse contractions in sperm and intergenerational sequence changes may play a role in reduced penetrance. Hum Mol Cenet 9: 2125-2130

Moseley ML, Zu T, Ikeda Y, Gao W, Mosemiller AK, Daughters RS, Chen C, Weatherspoon MR, Clark HB, Ebner TJ et al (2006) Bidirectional expression of CUG and CAC expansion transcripts and intranuclear polyglutamine inclusions in spinocerebellar ataxia type 8. Nat Genet 38: 758-769

Napierala M, Michalowski D, de Mezer M, Krzyzosiak WJ (2005) Facile FMR1 mRNA structure regulation by interruptions in CGG repeats. Nucleic Acids Res 33: 451-463

Nguyen L, Cleary JD, Ranum LPW (2019) Repeat-associated non-ATC translation: molecular mechanisms and contribution to neurological disease. Annu Reu Neurosci 42: 227-247

Pattamatta A, Nguyen L, Olafson HR, Scotti MM, Laboissonniere LA, Richardson J, Berglund JA, Zu T, Wang ET, Ranum LPW (2020) Repeat length increases disease penetrance and severity in C9orf72 ALS/FTD BAC transgenic mice. Hum Mol Genet 29: 3900-3918

Pulst S-M, Nechiporuk A, Nechiporuk T, Gispert S, Chen X-N, Lopes-Cendes I, Pearlman S, Starkman S, Orozco-Diaz G, Lunkes A et al (1996) Moderate expansion of a normally biallelic trinucleotide repeat in spinocerebellar ataxia type 2. Nat Genet 14: 269-276

Samukawa M, Hirano M, Saigoh K, Kawai S, Hamada Y, Takahashi D, Nakamura Y, Kusunoki S (2019) PSP-phenotype in SCA8: case report and systemic review. Cerebellum 18: 76-84

Sanpei K, Takano H, Igarashi S, Sato T, Oyake M, Sasaki H, Wakisaka A, Tashiro K, Ishida Y, Ikeuchi T et al (1996) Identification of the spinocerebellar ataxia type 2 gene using a direct identification of repeat expansion and cloning technique, DIRECT. Nat Genet 14: 277-284
Silveira I, Alonso I, Guimarães L, Mendonça P, Santos C, Maciel P, Fidalgo de Matos JM, Costa M, Barbot C, Tuna A et al (2000) High germinal instability of the (CTC)n at the SCA8 locus of both expanded and normal alleles. Am J Hum Genet 66: 830-840

Sobczak K, Krzyzosiak WJ (2005) CAG repeats containing CAA interruptions form branched hairpin structures in spinocerebellar ataxia type 2 transcripts. J Biol Chem 280: 3898-3910

Sonobe Y, Ghadge G, Masaki K, Sendoel A, Fuchs E, Roos RP (2018) Translation of dipeptide repeat proteins from the C9ORF72 expanded repeat is associated with cellular stress. Neurobiol Dis 116: 155-165

Stevanin G, Herman A, Durr A, Jodice C, Frontali M, Agid Y, Brice A (2000) Are (CTC)n expansions at the SCA8 locus rare polymorphisms? Nat Genet 24: 213, author reply 215

Stone J, Smith L, Watt K, Barron L, Zeman A (2001) Incoordinated thought and emotion in spinocerebellar ataxia type 8. J Neurol 248: 229-232

Tao Z, Wang H, Xia Q, Li K, Li K, Jiang X, Xu G, Wang G, Ying Z (2015) Nucleolar stress and impaired stress granule formation contribute to C9orf72 RAN translation-induced cytotoxicity. Hum Mol Genet 24: 2426-2441

Tian B, White RJ, Xia T, Welle S, Turner DH, Mathews MB, Thornton CA (2000) Expanded CUG repeat RNAs form hairpins that activate the doublestranded RNA-dependent protein kinase PKR. RNA 6: 79-87

Todd P, Oh S, Krans A, He F, Sellier C, Frazer M, Renoux A, Chen K-C, Scaglione K, Basrur V et al (2013) CGC repeat-associated translation mediates neurodegeneration in fragile $\mathrm{X}$ tremor ataxia syndrome. Neuron 78: $440-455$

Tusi SK, Nguyen L, Thangaraju K, Li J, Cleary JD, Zu T, Ranum LPW (2021) The alternative initiation factor elF2A plays key role in RAN translation of myotonic dystrophy type 2 CCUG*CAGG repeats. Hum Mol Genet 30: $1020-1029$

Wang Z-F, Ursu A, Childs-Disney JL, Guertler R, Yang W-Y, Bernat V, Rzuczek SG, Fuerst R, Zhang Y-J, Gendron TF et al (2019) The hairpin form of $r$ (G4C2)exp in C9ALS/FTD is repeat-associated non-ATC translated and a target for bioactive small molecules. Cell Chem Biol 26: 179-190.e12

Wen X, Tan W, Westergard T, Krishnamurthy K, Markandaiah SS, Shi Y, Lin S, Shneider NA, Monaghan J, Pandey UB et al (2014) Antisense proline-arginine RAN dipeptides linked to C9ORF72-ALS/FTD form toxic nuclear aggregates that initiate in vitro and in vivo neuronal death. Neuron 84: 1213-1225

White MR, Mitrea DM, Zhang P, Stanley CB, Cassidy DE, Nourse A, Phillips AH, Tolbert M, Taylor JP, Kriwacki RW (2019) C9orf72 Poly(PR) dipeptide repeats disturb biomolecular phase separation and disrupt nucleolar function. Mol Cell 74: 713-728.e716

Worth PF, Houlden H, Giunti P, Davis MB, Wood NW (2000) Large, expanded repeats in SCA8 are not confined to patients with cerebellar ataxia. Nat Genet 24: 214-215

Wright GEB, Collins JA, Kay C, MCDonald C, Dolzhenko E, Xia Q, Becanovic K, Drogemoller BI, Semaka A, Nguyen CM et al (2019) Length of uninterrupted CAG, independent of polyglutamine size, results in increased somatic instability, hastening onset of huntington disease. Am J Hum Genet 1116-1126

Zeman A, Stone J, Porteous M, Burns E, Barron L, Warner J (2004) Spinocerebellar ataxia type 8 in Scotland: genetic and clinical features in seven unrelated cases and a review of published reports. J Neurol Neurosurg Psychiatry 75: 459-465

Zhou Y, Yuan Y, Liu Z, Zeng S, Chen Z, Shen L, Jiang H, Xia K, Tang B, Wang J (2019) Genetic and clinical analyses of spinocerebellar ataxia type 8 in mainland China. J Neurol 266: 2979-2986

Zu T, Gibbens B, Doty NS, Gomes-Pereira M, Huguet A, Stone MD, Margolis J, Peterson M, Markowski TW, Ingram MAC et al (2011) Non-ATG-initiated 
translation directed by microsatellite expansions. Proc Natl Acad Sci USA 108: $260-265$

Zu T, Liu Y, Banez-Coronel M, Reid T, Pletnikova O, Lewis J, Miller TM, Harms MB, Falchook AE, Subramony SH et al (2013) RAN proteins and RNA foci from antisense transcripts in C9ORF72 ALS and frontotemporal dementia. Proc Natl Acad Sci USA 110: E4968-E4977

Zu T, Cleary JD, Liu Y, Bañez-Coronel M, Bubenik JL, Ayhan F, Ashizawa T, Xia G, Clark HB, Yachnis AT et al (2017) RAN translation regulated by muscleblind proteins in myotonic dystrophy type 2. Neuron 95: 1292-1305.e1295

Zu T, Pattamatta A, Ranum LPW (2018) Repeat-associated non-ATC translation in neurological diseases. Cold Spring Harb Perspect Biol 10: a033019
Zu T, Guo S, Bardhi O, Ryskamp DA, Li J, Khoramian Tusi S, Engelbrecht A, Klippel K, Chakrabarty P, Nguyen L et al (2020) Metformin inhibits RAN translation through PKR pathway and mitigates disease in C9orf72 ALS/ FTD mice. Proc Natl Acad Sci USA 117: 18591-18599

Zuker M (2003) Mfold web server for nucleic acid folding and hybridization prediction. Nucleic Acids Res 31: 3406-3415

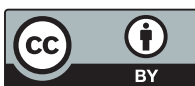

License: This is an open access article under the terms of the Creative Commons Attribution License, which permits use, distribution and reproduction in any medium, provided the original work is properly cited. 